University of Louisville

ThinkIR: The University of Louisville's Institutional Repository

\title{
The neuropsychological profile of older adult musicians and non- musicians : implications for cognitive reserve in late life.
}

Jessica Vemich Strong, University of Louisville

Follow this and additional works at: https://ir.library.louisville.edu/etd

Part of the Clinical Psychology Commons

\section{Recommended Citation}

Strong,, Jessica Vemich, "The neuropsychological profile of older adult musicians and non-musicians : implications for cognitive reserve in late life." (2015). Electronic Theses and Dissertations. Paper 2245. https://doi.org/10.18297/etd/2245

This Doctoral Dissertation is brought to you for free and open access by ThinkIR: The University of Louisville's Institutional Repository. It has been accepted for inclusion in Electronic Theses and Dissertations by an authorized administrator of ThinkIR: The University of Louisville's Institutional Repository. This title appears here courtesy of the author, who has retained all other copyrights. For more information, please contact thinkir@louisville.edu. 
THE NEUROPSYCHOLOGICAL PROFILE OF OLDER ADULT MUSICIANS AND NON-MUSICIANS: IMPLICATIONS FOR COGNITIVE RESERVE IN LATE LIFE

\author{
By \\ Jessica Vemich Strong \\ B.A./B.M., DePauw University, 2009 \\ M.A., University of Louisville, 2012

\begin{abstract}
A Dissertation
Submitted to the Faculty of the

College of Arts and Sciences of the University of Louisville

in Partial Fulfillment of the Requirements

for the Degree of
\end{abstract} \\ Doctor of Philosophy in Clinical Psychology \\ Department of Psychological and Brain Sciences \\ University of Louisville \\ Louisville, Kentucky
}

August 2015 

THE NEUROPSYCHOLOGICAL PROFILE OF OLDER ADULT MUSICIANS AND NON-MUSICIANS: IMPLICATIONS FOR COGNITIVE RESERVE IN LATE LIFE

\author{
By \\ Jessica Vemich Strong \\ B.A./B.M., DePauw University, 2009 \\ M.A., University of Louisville, 2012 \\ A Dissertation Approved on
}

June 22, 2015

By the following Dissertation Committee:

Benjamin Mast, Ph.D., Dissertation Director

Suzanne Meeks, Ph.D.

Robert Friedland, M.D.

Keith Lyle, Ph.D.

Paul Salmon, Ph.D. 


\section{ACKNOWLEDGMENTS}

I would like to thank my advisor, Dr. Ben Mast, for all his assistance and advice over the past five years, and for being a role model in his professional career and personal life. I would also like to thank the members of my committee for their input while designing this study and in the final product, including Dr. Suzanne Meeks, Dr. Paul Salmon, Dr. Keith Lyle, and Dr. Robert Friedland. The support from my partner, Tim, was unparalleled throughout this project, and particularly in the final few months.

Finally, I would like to thank my parents, Tom and Nancy, and my brother, Matt, for their unconditional love. 


\begin{abstract}
THE NEUROPSYCHOLOGICAL PROFILE OF OLDER ADULT MUSICIANS AND NON-MUSICIANS: IMPLICATIONS FOR COGNITIVE RESERVE IN LATE LIFE Jessica V. Strong
\end{abstract}

June 22, 2015

Published literature studying children and adults musicians suggests significant differences in neuroanatomy, in brain regions that include the auditory and motor cortices, language centers, and frontal regions and tracts. Studies examining cognitive correlates to these neuroanatomical differences have consistently found that children and adult musicians have better cognitive abilities in the domains of language, verbal or non-verbal memory and executive function. Only one study has examined the differences in cognitive performance between older adult musicians and non-musicians to see how normal age-related cognitive changes may affect these differences. The current study compared cognitive test performance among older adult non-musicians, low-activity musicians ( $<9$ years of private lessons), and high-activity musicians ( $>10$ years of private lessons).

The results of the current study found that musicians performed significantly better than non-musicians on some tests of language (confrontation naming, BNT), visual spatial ability (Block Design and Judgment of Line Orientation), and aspects of executive function (Delis-Kaplan Executive Function System - Color Word Interference). Significant differences were found between high-activity and non-musicians, and low- 
activity musicians' scores generally fell in between these groups, suggesting a linear trend. The results also showed that within the two musician groups, number of years in private lessons was related to scores on verbal memory tests, and number of hours spent practicing at peak of training was related to one test of language and executive function (COWA-FAS), and visual spatial ability (Block Design). Age of beginning an instrument was not related to any test scores. Finally, regression analyses found that membership in either musician group (i.e., low-activity or high-activity) predicted scores on confrontation naming (BNT), one test of visual spatial ability (Judgment of Line Orientation), and one test of executive function (Color-Word Interference).

The current study provides additional evidence to support increased cognitive performance within the domains of language, visual spatial ability, and executive function in older adult musicians when compared to non-musicians. However, the sample was relatively homogenous in terms of ethnicity, and was highly educated. Future studies should attempt to replicate this information in more ethnically and racially heterogeneous groups as well as with samples of lower education. 
TABLE OF CONTENTS

PAGE

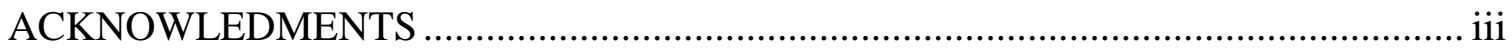

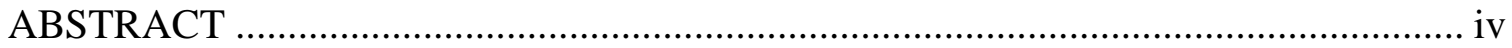

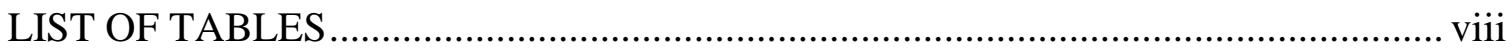

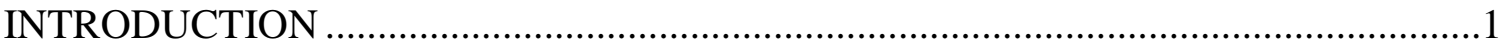

Neuroanatomical Differences Between Musicians and Non-Musicians ..........................2

Cognitive Differences between Musicians and Non-musicians ....................................5

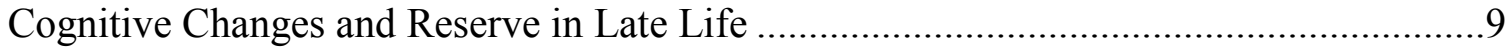

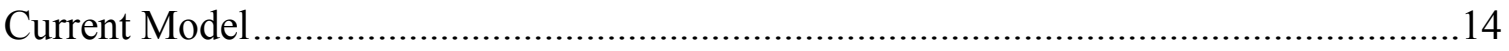

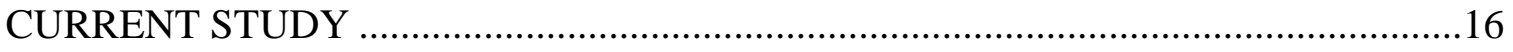

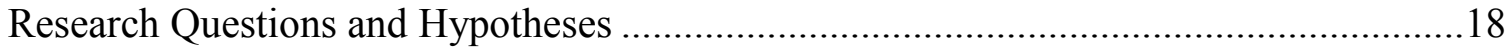

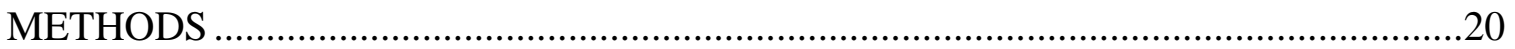

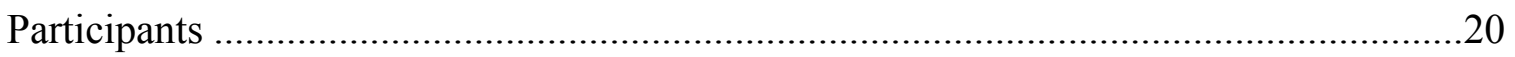

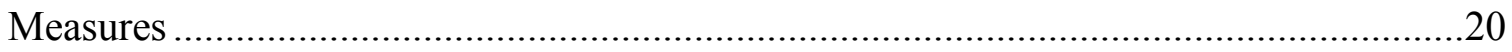

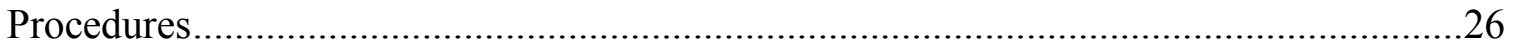

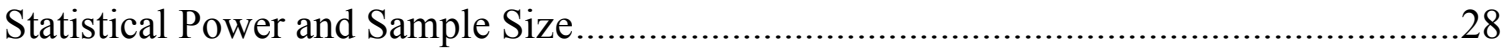

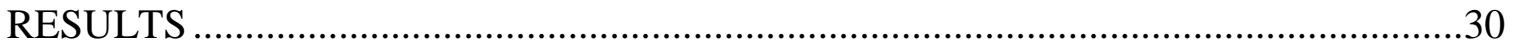

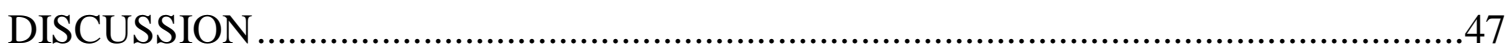


Executive Function and Music Training.

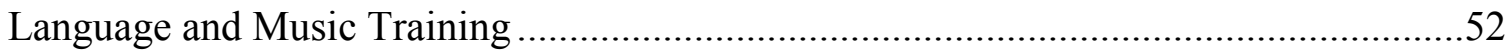

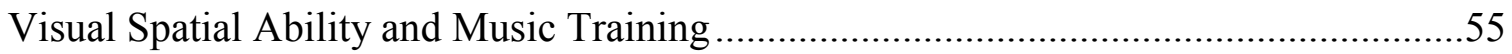

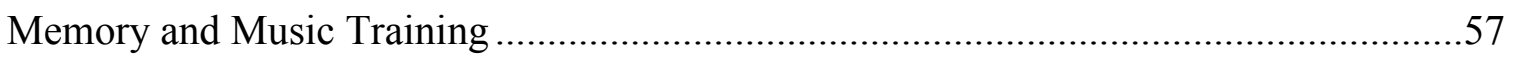

Predictors of Cognition Within Music Trained Elders ………........................................60

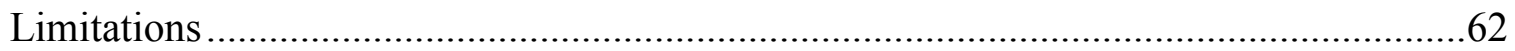

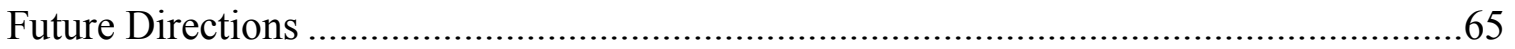

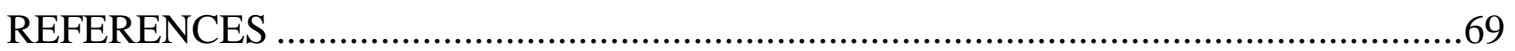

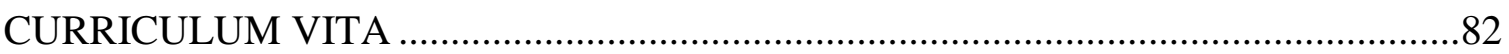




\section{LIST OF TABLES}

TABLE

PAGE

1. Total Sample Demographics............................................ 31

2. Music Sample Demographics........................................... 32

3. Raw Score Means and Standard Deviations of Cognitive Scores...................33

4. Correlations of Music Training Variables.................................... 37

5. Correlations of Music Training and Cognitive Scores...........................38

6. Beta Weights of Predictors on Cognitive Scores for Total Sample..................39

7. Beta Weights of Predictors on Cognitive Scores for Musician Sample..............45 


\section{INTRODUCTION}

There has been a recent increase in research interest related to the effects of music on a variety of other factors, including cognition and neuroanatomy. The activities required by a musician on a regular basis involve activation of specific brain areas and

high levels of communication among these brain areas. Motor and auditory networks are called upon for technical playing and sensory feedback. Frontal and prefrontal lobes are involved in organizing the precise and detailed sequence of events required to play, including which key or button to press at the correct time. The temporal and occipital lobes are involved in tasks such as reading and memorizing a piece of music. Although the specific musical skills that involve one part of cortex or another are developed separately, all skills and brain regions are integrated with each piece of music the musician plays. Throughout their careers, musicians learn new music, requiring these skills, and therefore, the brain structures, to be used in novel ways.

This study tested the hypothesis that musical training contributes to better cognitive functioning in late life by examining differences on neuropsychological test performance between older adults who had musical training and those who did not. Few studies have been published that examine differences between older adult musicians and non-musicians. Only one group (Hanna-Pladdy \& Gajewski, 2012; Hanna-Pladdy \& MacKay, 2011) has specifically examined neuropsychological functioning of older adult musicians compared to non-musicians, and they failed to account for critical 
covariates,including social activity level and general health conditions (study described in more detail below). There remains a paucity of empirical studies integrating the literature from the fields of lifespan development, music cognition, and cognitive aging to examine how extensive musical training in childhood and across the lifespan may impact late life cognition. In the sections below, literature from these fields will be reviewed and synthesized to provide an appropriate background to the proposed research questions.

Neuroanatomical Differences between Musicians and Non-musicians

Study design is of utmost importance in research examining neuroanatomical changes in children involved in music lessons. Longitudinal studies with random assignment are necessary to increase the validity of the findings: this design enables researchers to speak to the possibility of pre-existing differences between children who take music lessons and those who do not. Studies using longitudinal designs suggest that early music training causes neuroanatomical change that cannot be accounted for by other life experiences (Hyde et al., 2009; Schlaug, Norton, Overy, \& Winner, 2005). These changes include increased grey matter volume compared to non-musicians in regions responsible for integrating sensory information (Gaser \& Schlaug, 2003), language comprehension (Bermudez \& Zatorre, 2005), and language production (Gaser \& Schlaug, 2003).

One key longitudinal study that exemplifies how early music training can affect brain structure and development compared MRI scans of children randomly assigned to half hour private piano lessons to a control group of children (Hyde et al., 2009). There were no significant differences in brain images at baseline. Fifteen months later, after controlling for typical brain development, there were significant differences in the brain 
volume of the children in music lessons in the right precentral gyrus (primary motor area), the corpus callosum, and the right primary auditory region, as well as unhypothesized changes in the frontal regions bilaterally, and left posterior pericingulate regions, involved in integrating the visual and limbic systems (e.g., visual and emotional information).

Cross-sectional neuromaging studies have examined whether brain differences seen between musicians and non-musicians in childhood are maintained into adulthood. When compared to non-musicians, studies have found that adult musicians have increased grey matter volume bilaterally in the primary motor cortices, somatosensory cortex, premotor regions, and superior parietal regions, responsible for integrating sensory information (Gaser \& Schlaug, 2003), right superior temporal gyrus, location of the primary auditory cortex (Bermudez \& Zatorre, 2005), and the left inferior frontal gyrus, location of Broca's area, involved in language. Gaser and Schlaug (2003) also found a linear trend in the densities of these areas and the age at which the individual began studying an instrument. In other words, the earlier an individual began playing an instrument, the denser these structures were.

More specific structures, including sub-regions of Broca's area (Abdul-Kareem, Stancak, Parkes, \& Sluming, 2011;), the corpus callosum (Schlaug, Jäncke, Huang, Staiger, \& Steinmetz, 1995), the arcuate fasiculus (AF; Halwani, Loui, Rüber, \& Schlaug, 2011), and the hippocampus (Herdener et al., 2010) have been examined for differences between musicians and non-musicians. Abdul-Kareem and colleagues (2011) found increased grey matter volume in male musicians in Broca's area sub-regions responsible for syntactic processing and phonological working memory in language processing but 
found no differences between the musicians and non-musicians in regions of Broca's area responsible for semantic processing, rhyming, and lexical decision making. This finding suggests that musicians have increased neuronal density in some structures, which may lead to differences in cognition associated with these structures, for example verbal working memory. The hippocampus has also been found to differ between musicians and non-musicians, with implications for aging and dementia due to its role in memory and learning (Herdener et al., 2010). Cross-sectionally, music students showed increased activation in the left anterior hippocampus, when presented with tones that deviated from an original pattern in comparison to non-music students. Longitudinally, music students underwent imaging before entering university and again after their first year of college level music training, which included 2 semesters of intensive aural skills training. The study found differences in activation patterns in the right planum temporale - an area that integrates perception of a sound in the auditory cortex with stored representations of the sound, in other words, pitch discrimination. The authors suggested that these differences in musicians support the hippocampus as a "novelty detector," which means that it compares new stimuli to existing representations (i.e., memories). The implications for differences in the functioning and activation of the hippocampus between musicians and non-musicians are noteworthy, particularly when considering the sensitivity of this structure to normal age-related atrophy (Raz \& Rodrigue, 2006) and the role of the hippocampus in diseases of late life such as Alzheimer's disease (AD).

Further examination of specific neuroanatomical structures has revealed increased density of the corpus callosum, a structure that is a key player in communication between hemispheres (Schlaug et al., 1995). Another study examined the differences among 
instrumentalists, vocalists, and non-musicians in the AF, which is a white-matter tract that connects temporal and frontal brain regions (Halwani et al., 2011). Both groups of musicians (instrumentalists and vocalists) had a denser AF bilaterally compared to nonmusicians. Singers had greater AF volume in the left hemisphere compared to instrumentalists, but there were no differences between these groups in the right hemisphere. This difference could again be explained through the training that musicians receive, and specifically, that vocalists' skill sets include more speech, an ability that is often more lateralized to the left hemisphere. These findings (denser corpus callosum and AF) suggest greater connectivity among brain regions in musicians. This is an important point in the later discussion of cognitive reserve.

The neuroanatomical features found in children who take music lessons and also found in adult musicians likely have some functional cognitive correlates. For example, musicians have regularly been found to have increased grey matter in language areas of the brain (e.g., Broca's area; Abdul-Kareem et al., 2011) and have been found to have better language abilities beginning in childhood (Ho, Cheung, \& Chan, 2003; Moreno et al., 2011). The next section discusses these cognitive differences between musicians and non-musicians in more detail in order to inform hypotheses about which domains might differ between these groups.

\section{$\underline{\text { Cognitive Differences between Musicians and Non-musicians }}$}

Studies with children worldwide have shown that participating in structured musical activities outside of school increases academic achievement (Halwani et al., 2011; Ho et al., 2003), motor skills (Costa-Giomi, 2005; Hyde et al., 2009; Schlaug et al., 2005), and auditory discrimination skills (Fujioka, 2006; Shahin, Roberts, \& Trainor, 
2004). Within cognitive domains, most research has focused on verbal memory and verbal abilities. Studies have suggested that overall language skills improve significantly in children randomly assigned to receive music lessons. A study by Anvari, Trainor, Woodside, and Levy (2002) found evidence that phonemic awareness and reading were significantly correlated with general musical ability in four year olds. The authors proposed that the relationship between phonological awareness and music perception supports the existence of a common auditory mechanism responsible for both language and music domains.

One study found that randomly assigning children to participate in a music ensemble (e.g., orchestra) significantly affected verbal memory when compared to a control group of age and IQ matched peers (Ho et al., 2003). Interestingly, children who subsequently discontinued music participation did not decline in verbal memory. Ho and colleageus (2003) found that although the verbal memory scores of this group of children stopped improving, they still showed an advantage compared to their peers who were never enrolled in music ensembles.

The consistent pattern of higher verbal abilities and verbal memory in children enrolled in music lessons (Ho et al., 2003; Moreno et al., 2011) is also found in adult musicians (Brandler \& Rammsayer, 2003; Brown, Martinez, \& Parsons, 2006; Jakobson, Lewycky, Kilgour, \& Stoesz, 2008). However, some have proposed that rather than strengths in verbal memory because of the similarity in structure between music and language, adult musicians should have stronger visual memory than non-musicians because of the way musical notation is presented (Jakobson, et al., 2008). At least two studies have examined verbal and/or visual memory (Brandler \& Rammsayer, 2003; 
Jakobson et al., 2008), and both found that musicians showed significantly better recall in verbal memory compared to non-musicians. Only one of the two studies (Jakobson et al., 2008) examined visual memory in addition to verbal memory and found that adult musicians also had higher visual memory than non-musicians.

Other cognitive domains have also been assessed (e.g., executive function, visuospatial ability), but with much less frequency in the literature. Only one published study found significant differences in executive function in adult musicians. Bialystok and DePape (2009) compared monolingual musicians, bilingual, and monolingual nonmusicians. They found that the groups performed equally on intelligence tests, but musicians and bilinguals exhibited higher executive spatial abilities compared to the controls.

Only one study to date has directly compared neuropsychological functioning between older adults with musical training and older adults without musical training. Musicians were grouped into high-activity (more than 10 years of musical training) or low-activity (1-9 years of musical training) and compared to non-musicians (HannaPladdy \& Gajewski, 2012; Hanna-Pladdy \& MacKay, 2011) on neuropsychological test performance. Older adult musicians had better performance on executive function tasks, some language tasks (e.g., confrontation naming), and delayed visual memory than nonmusicians. Unfortunately this study controlled only for age and physical activity, failing to control for general cardiovascular health conditions or social activity, both of which are related to cognitive functioning (Colcombe \& Kramer, 2003; Richards, Hardy, \& Wadsworth, 2003; Weuve et al., 2004). Overall, results of this study showed that there 
are differences in the cognitive functioning of musicians and non-musicians during later adulthood, but could not rule out the possibility of other confounding variables.

Other studies examining older adult musicians have not tested a range of cognitive domains (Nevriana, Riono, Rahardjo, \& Kusumadjati, 2013), did not study neuropsychological functioning at all but rather dementia diagnosis (Balbag, Pedersen, \& Gatz, 2014), or examined musical knowledge and its relationship to semantic and episodic memory (Gooding, Abner, Jicha, Kryscio, \& Schmitt, 2013). Nevriana et al. (2013) studied correlations on scores of a common cognitive screening measure (MiniMental State Exam, MMSE) of musicians in nursing homes who were involved in music activities and those who were not. They found that there was a correlation between MMSE scores and lifetime musical activities. Although this approach sheds some light onto cognitive differences between those who are involved in music and those who are not, it does not examine specific cognitive domains. Balbag et al. (2014) studied discordant twins, in which one twin reported experience playing a musical instrument and the other twin did not. After controlling for sex, education, and physical activity, they found that playing a musical instrument was related to lower likelihood of dementia and cognitive impairment in late life. Gooding et al. (2013) administered a test of musical knowledge and grouped individuals into low-, medium-, and high knowledge groups. Although musical knowledge is likely highly correlated with music training, this approach differs from asking questions directly related to music training (e.g., length of time in lessons). They found that high knowledge musicians had better episodic memory and semantic memory, which may suggest that early or mid-life music training contributes to cognitive reserve. This study controlled for age, sex, and education, but 
did not control for physical or social activity levels. These variables, including age, education, social and physical activity levels, can all have unique effects on cognition in late life. In order to better understand how musical training may affect the brain in late life, the next section reviews the literature on these variables and their relationship to cognitive aging and reserve.

\section{Cognitive Changes and Reserve in Late Life}

The cognitive aging literature suggests that throughout the aging process brain atrophy occurs in specific neuroanatomical regions, rather than globally. Regions and structures that seem to be vulnerable to the aging process include the hippocampus and subcortical white matter, as well as the prefrontal cortex. There are also other factors that may affect the density of these structures either positively or negatively including hypertension or other vascular risk factors, as well as physical fitness and aerobic health (Raz \& Rodrigue, 2006).

There are some cognitive correlates of the neuroanatomical changes seen across the life span as well, and longitudinal studies have documented normal cognitive changes across the lifespan (e.g., Berlin Aging Study - Baltes \& Mayer, 2001; Seattle Longitudinal Study or SLS - Schaie, 1993). Cognitive domains that are particularly vulnerable to aging effects include processing speed (Ghisletta, McArdle, \& Lindenberger, 2006; Lindenberger \& Baltes, 1997) and memory (Salthouse, 2004). However, other domains, including crystallized knowledge (like factual knowledge and vocabulary), remain stable and indeed may even increase across the life span into the 50s and 60s (Lindenberger \& Baltes, 1997). Some studies have found that processing speed and memory are affected more severely as time goes on. In other words, as one ages, 
these abilities decrease more quickly (Salthouse, 2004; Verhaeghen \& Salthouse, 1997). However, when decreases in processing speed due to aging are accounted for, the magnitude of change in these fluid abilities is reduced significantly (Schaie, 1993), suggesting that processing speed is a key factor in accounting for decreases in other cognitive domains.

The SLS has also identified some individual difference factors that account for age-related changes in cognition including chronic disease, socioeconomic status, intellectual environment, personality style, and maintenance of processing speed levels (Schaie, 1993). Importantly, the SLS findings suggested that training a cognitive ability (e.g., exercises to enhance memory) maintained positive effects up to 7 years later. These findings suggest that the aging process is complex, but that the plasticity of the brain, even at later life stages, may be able to compensate for damage.

The theory of cognitive reserve (CR) has been proposed to describe the relationship between level of brain pathology (e.g., size of lesion) and functional ability. $\mathrm{CR}$ is an abstract construct that attempts to explain how the brain uses reserves developed throughout the lifespan to compensate for injury and disease (Stern, 2003). It is consider an "active model" because the threshold for exhibiting functional impairments due to brain pathology is not a fixed value, but rather can change across the lifespan. Although $\mathrm{CR}$ is a cognitive concept, it has neural implications. There are two underlying proposed neural mechanisms (Stern, 2002), including neural reserve and neural compensation. Neural reserve describes discrepancies in the reserve levels of one cognitive domain compared to another. For example, if the brain sustains damage, one cognitive domain may maintain an ability to function near normal levels compared to another cognitive 
domain that presents as impaired. Within this mechanism, the domain that retained functioning had a higher level of initial reserve, allowing it to maintain higher levels of function in spite of damage. Neural compensation explains how the brain re-routes or counteracts damage by using an alternative network in place of the damaged network.

The concept of CR accounts for individual differences based on genetics, education, and an individual's life involvement in leisure or intellectual activities (e.g., playing a musical instrument). Stern (2009) suggested that CR is a result of environmental exposure that shifts throughout the lifetime to reflect personal experience at that life stage. According to Stern (2003), this does not imply that these individuals' brains are structured differently, but rather that they may be able to function more efficiently. Relevant to the current study is the idea that subtle, mild cognitive declines that occur with aging may be delayed through reserves that were gained, for example, via specialized training in music or continued participation in music activities.

Because $\mathrm{CR}$ is an abstract construct, there are issues validly measuring both the construct itself and its relationship to covariates. In the literature, CR is measured using proxy variables, or a variable that stands in place of the immeasurable CR. Factors that represent cognitive activities or cognitive exposure throughout the lifetime, like education or occupational attainment (Barulli \& Stern, 2013) are the most common proxy variables for CR. Using education as a proxy theoretically makes sense, in that educational attainment can contribute to both neural changes and cognitive changes, and is one of the strongest factors associated with decreasing risk for dementia (Bowirrat, Friedland, Farrer, Baldwin, \& Korczyn, 2002). CR could help explain how education can predict the level of brain pathology an individual can sustain before showing functional 
deficits. However, there are other possible ways that education is linked to CR. For example, Jones et al. (2010) suggested that education may be related to performance on neuropsychological tests because of CR, because of childhood IQ, other cognitive skills that influence educational attainment, or non-linear rates of age related decline. Another possible confounding factor is that education and occupation are highly related to socioeconomic status. As demonstrated by Jones et al. (2010), research continues to struggle to accurately measure this latent $\mathrm{CR}$ variable.

Correlates of Cognitive Reserve. There are a few possible explanations for the relationship between $\mathrm{CR}$ and education. People with higher education may build more neural plasticity because they are required to think about abstract concepts in novel ways, which then leads to higher levels of CR. Alternatively, people with a higher educational attainment may make different life choices and it is these life styles that lead to higher cognitive functioning. In any case, the relationship between these factors has been well established and suggests that educational attainment lowers risk factor for dementia (Bowirrat et al., 2002; Di Carlo et al., 2002; Karp, 2004).

Another factor understood to contribute to $\mathrm{CR}$ and predict greater cognitive function later in life is social activity. Studies have found that adults who are engaged in more social activities are at a reduced risk for developing dementia (Fratiglioni, Wang, Ericsson, Maytan, \& Winblad, 2000; Wang, 2002), indicating that they may have higher levels of CR. One study (Barnes, Mendes de Leon, Wilson, Bienias, \& Evans, 2004) found that in both African American and Caucasian older adults, the effects of a larger social network on cognitive level and reducing cognitive decline were significant even after controlling for SES, cognitive engagement, physical activity, depression, and 
chronic medical conditions. Results from these studies suggest that social activity contributes uniquely to cognitive function, independent of other factors.

A third factor that has been found to contribute to levels of reserve is physical activity and physical health. Physical activity and the maintenance of cognitive ability in older adults has been studied extensively and findings suggest that independent of social and other cognitive factors, physical activity protects against cognitive decline in late life (Abbott, 2004; Richards et al., 2003; van Gelder et al., 2004; Weuve et al., 2004). In addition, a meta-analysis of studies using physical activity as an intervention for cognitive decline (Colcombe \& Kramer, 2003) found that adults who were active, or increased their activity, maintained higher levels of cognition for longer compared to less active peers. The largest effects were seen in executive abilities, but overall differences depended on the length of the intervention and duration of training sessions. These studies suggest that people who are more physically active may have higher levels of reserve in late life.

The findings from the above CR literature suggest several important conclusions. $\mathrm{CR}$ is related to education, possibly due to the cognitive demands and flexibility required in higher education settings. However, after controlling for education, other factors such as physical activity (Abbott, 2004; Weuve et al., 2004) and social activity (Barnes et al., 2004; Fratiglioni et al., 2000; Wang, 2002) have also been found to be highly predictive of cognition in late life, suggesting that these activities also contribute to levels of reserve in late life. Finally, the variable of CR may be difficult to capture accurately based on the field's current understanding, leading to issues in the validity of measuring both CR and its correlates. 


\section{Current Model of Cognitive Reserve and Implications for Music Training}

A model proposed by Richards and Deary (2005; see Figure 1) suggests that CR represents premorbid cognition with other factors such as brain size and neuronal density, early environmental experiences, and extent of brain lesions, that collectively contribute to the clinical expression of brain injury. Theoretically, one could argue that as early musical training contributes to the formation of new connections among neurons, these new connections would influence levels of $\mathrm{CR}$ and perhaps serve as a protective factor against even normal cognitive decline in older age. For example, musicians may have more density in the hippocampus (Herdener et al., 2010), which is a brain structure that has been shown to be sensitive to decreases in density even in normal aging ( Raz \& Rodrigue, 2006).

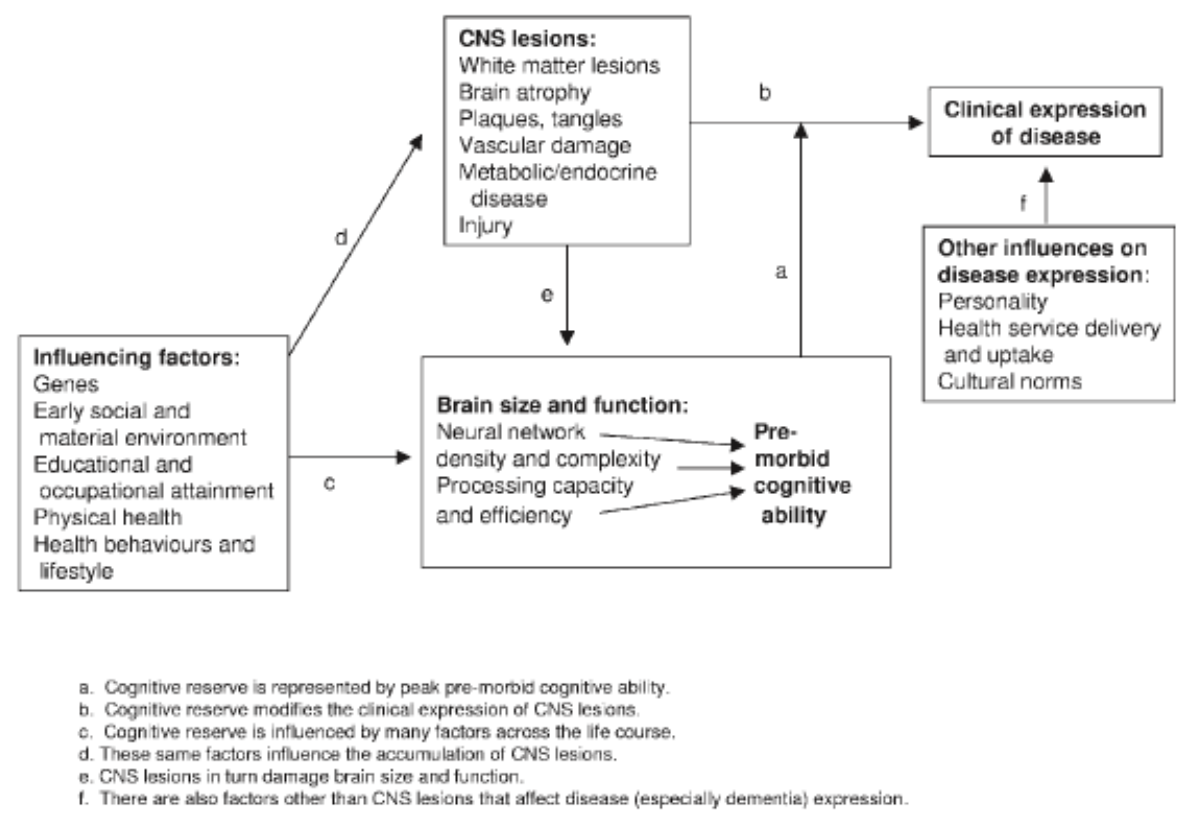

Figure 1: Richards and Deary (2005) model of CR across the lifespan 
The current study attempted to expand part of this model by examining how early musical training contributes to CR (see Figure 2). The focus of the current study was on the cognitive function of older adults and the relationship between cognition and other influencing factors including early environment, physical and social activity, and premorbid cognitive ability. As studies have found decreases in specific skills that include processing speed and memory (Ghisletta et al., 2006; Salthouse, 2004; Verhaeghen \& Salthouse, 1997), this study attempted to examine cognitive functioning as a proxy for age-related brain changes that differentiate between the two subgroups (i.e., musicians and non-musicians). It is understood that cognitive abilities are not a pure indicator of brain health, but the addition of a variable for specialized musical training to the model is the key piece to be examined in the current study.

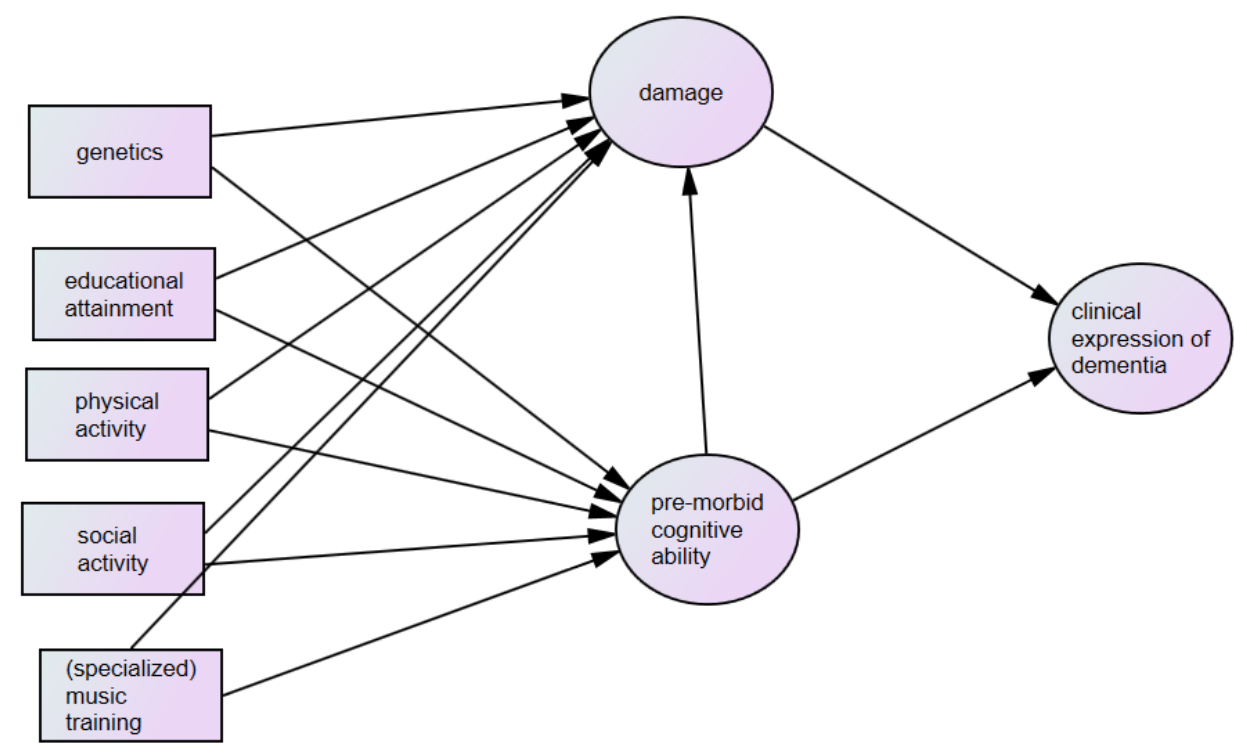

Figure 2: Adapted from Richards and Deary (2005), showing the unique contribution of music as a factor in pre-morbid cognitive ability and expression of damage to the brain. 


\section{CURRENT STUDY}

This study is the only study to date that examined the cognitive function of healthy older adults, comparing those with musical training and those without, while specifically controlling for other covariates of cognitive functioning. The study attempted to replicate a previous study by Hanna-Pladdy and MacKay (2011) and HannaPladdy and Gajewski (2012), who recruited 70 older adults (mean age 70) and divided participants into three groups based on their musical training; the groups were divided based on those who had lessons for more than 10 years ("high-activity;" n=22), those who had lessons for 1-10 years ("low-activity;" n=27), and those with less than 1 year or no musical training ("non-musicians;" $n=21$ ). All participants were healthy older adults who were fully independent on all activities of daily living and there were no significant differences among the groups on their responses to an exercise questionnaire. Participants completed a battery of neuropsychological measures. The only musical experiences that were reported in these studies were the age at which an individual started playing, current playing behaviors, and the instrument(s) they played. The majority of the musicians played the piano (over $50 \%$ in both low- and high-activity groups).

Hanna-Pladdy and MacKay (2011) reported no significant differences between groups based on verbal learning and memory recall measures (CVLT total, delayed recall, recognition). They found significant differences between high-activity musicians and non-musicians on nonverbal recall (measured by Visual Reproduction I and II from 
Wechsler Memory Scales); however, the differences between subgroups of musicians as well as low-activity and non-musicians were non-significant. High activity musicians were significantly faster than low activity musicians on Trails A and significantly faster than non-musicians on Trails B. On confrontation naming (BNT), high activity musicians were significantly better at than non-musicians. Hanna-Pladdy and MacKay (2011) also used discriminate analyses to identify the tasks that were more accurate and differentiating between music groups. These tasks included Trails B, Visual Reproduction, and BNT. Finally, regression analyses revealed that the age the person began playing an instrument was the best predictor for non-verbal immediate recall, whereas years of musical activity was the best predictor of delayed non-verbal memory. These predictors remained in place even after controlling for age, education, estimated verbal intelligence and physical activity.

In a second publication using the same sample, Hanna-Pladdy and Gajewski (2012) ran partition analyses to measure the effect of general activity level and which aspects of music training affected cognitive function. They found more evidence for a sensitive period, such that musicians who began lessons before the age of 9 had better scores on verbal working memory. Musical involvement both as a child and as an older adult explained variability on tests in both verbal and visual spatial domains, whereas general activity level did not explain variability in these areas. Finally, they reported that current musical engagement offset lower education levels within the visual spatial domain.

The current study applied elements of Richards and Deary's model (2005) to a sample of older adults in an attempt to replicate the study by Hanna-Pladdy and MacKay 
(2011). Specifically, musicians and non-musicians were compared on neuropsychological tests to establish differences in some cognitive domains, as were found in the previous study. In addition to exploring cognitive differences, the current study also statistically controlled for levels of education, physical activity, social activity, and overall health conditions.

\section{$\underline{\text { Research Questions and Hypotheses }}$}

1. To what extent are there differences in cognitive performance between older adult musicians and non-musicians and in what cognitive domains? Based on previous studies, it was hypothesized that differences would be found between musicians and non-musicians in the domains of executive function and delayed visual and verbal memory, such that musicians would show significantly higher abilities in these areas.

2. If differences in cognitive domains are found, do these differences remain even after controlling for education and physical and social activity levels and health? It was hypothesized that cognitive differences between musicians and non-musicians would remain significant even after controlling for these covariates.

3. What music training variables are related to neuropsychological test scores? For example, is there a relationship between the number of years a musician was involved in intensive training and a specific cognitive score? It was hypothesized that both number of years an individual was engaged in musical training and the age at which he/she began playing would significantly contribute to differences in cognitive scores. It was hypothesized that there 
would be a negative relationship between the age a musician began playing and his or her cognitive ability, after controlling for the number of years they played. It was hypothesized that amount of time spent practicing an instrument (in hours) would be positively correlated with cognitive performance.

4. What factor has the strongest unique contribution to cognitive performance, among the variables of education, age, physical activity, social activity, physical activity, overall health, and musical training? It was hypothesized that age would have the strongest contribution to cognitive performance for both groups, but that each of the variables mentioned above, including music training, would show unique contributions to cognitive performance. 


\section{METHODS}

\section{$\underline{\text { Participants }}$}

The current study included musicians and age non-musicians controlling for education, physical and social activity, and overall health in an attempt to replicate and extend the findings of Hanna-Pladdy and MacKay (2011; described above). Inclusion criteria were as follows: Participants were 65 years old or older. Each was able to independently provide full written informed consent. Musicians were instrumentalists; singers were excluded for the purposes of replication. All potential participants were screened via a phone interview and asked to self-report mood (e.g., major depression) or neurological (e.g., AD, stroke, Parkinson's disease) disorder. If a disorder was reported or the participant showed evidence of significant cognitive impairment or psychoses, the participant was excluded.

\section{$\underline{\text { Measures }}$}

A battery was designed to assess a range of cognitive functions that have been demonstrated to show age-related declines. Many of the same instruments were used in the study by Hanna-Pladdy and MacKay (2011). Tests were chosen based on the quality and availability of appropriate norms. The most recent standardization samples from the test publisher were used whenever possible to derive standard scores. All tests were administered with paper and pencil. 
Premorbid intellectual functioning. The Wide Range Achievement Test (WRAT)-3 Reading was originally published in 1936 as a part of the Wechsler-Bellevue. The most current version was developed in 1993 (Wilkinson, 1993) and is designed to measure reading ability and pre-morbid intellectual functioning. This test has been found to have strong test-retest reliability (0.90) in healthy older adults and can be used as an estimate of baseline intellectual functioning prior to any age-associated cognitive decline (Ashendorf, Jefferson, Green, \& Stern, 2009).

Executive Function. The Trail Making Test was developed in 1938 as part of the Army Individual Test Battery (Partington \& Leiter, 1949) before it was adapted by Reitan and added to the Halstead-Reitan Battery. It is a test made of two parts that measures processing speed, visual tracking, and executive function. The test has numbers or letters in circles randomly situated around the page. Trails A requires the participant to connect numbers in order as quickly as possible, incorporating processing speed and visualperceptual abilities. Trails B incorporates aspects of executive function (e.g., set switching and mental control) by requiring alternation between numbers and letters (1-a2-b). Studies suggest that the number of seconds to complete Trails B, minus the number of seconds to complete Trails A represents a relatively clean indicator of executive function (Arbuthnott \& Frank, 2000; Sánchez-Cubillo et al., 2009). Times on Trails A and B are highly influenced by age and education and generally range from around 30 seconds (Trails A) to 120 seconds (Trails B). A standard cutoff of 300 seconds was used based on the administration manual. Normative data accounts for age and education when calculating standardized scores from speed at which the task was finished. The Trail Making Test test-retest reliability for older adults has been found to be $0.53-0.64$ for 
Part A and 0.67-0.72 for Part B. Inter-rater reliability has been reported to be quite high (Part $A=0.94$, Part $B=0.90)$. Parts A and B correlate well with each other (0.31-0.60) and with other measures of processing speed and cognitive flexibility (see Spreen \& Strauss, 1998).

The Stroop task is another executive function task, one that requires the participant to read a list of color words written in different colored ink (e.g., the word "red" written in green ink) - first by reading the words as written, then reporting color squares, and finally by reading the color of ink in which the word is written. The DelisKaplan Executive Functioning System (D-KEFS) is a version of the Stroop task with a fourth added inhibitory/switching component (Delis, Kramer, Kaplan, \& Holdnack, 2004). The Color-Word Interference subtest has been found to have adequate internal consistency and test-retest reliability (0.70-0.79; see Spreen \& Strauss, 1998).

Attention and Working Memory. The Ruff Figural Fluency Test (RFFT) measures how many unique responses a participant can draw in five one-minute trials. It was designed to be a non-verbal equivalent of the verbal fluency tasks described below and was developed in 1996 (Ruff, 1996). The RFFT shows some practice effects in multiple studies in test-retest reliability (0.71-0.88); however, it shows strong inter-rater reliability (0.80-0.89) and validity as a measure of executive function and attention (e.g. Ross, Foard, Hiott, \& Vincent, 2003).

Digit Span, taken from the Wechsler Adult Intelligence Scale (WAIS-IV; Wechsler, Coalson, \& Raiford, 2008), requires participants to repeat a string of numbers that is progressively longer. This task includes a forward condition, a backward condition, and a sequenced condition, which asks the participant to organize the numbers 
in order, starting with the lowest number. The Digit Span test has high internal consistency reliability (average 0.93 for individuals older than 65) and loads onto a working memory factor within a four factor model of verbal comprehension, perceptual reasoning, and processing speed (Wechsler et al., 2008).

Language. Animal Naming and the Controlled Oral Word Association Test (COWAT-FAS) measure verbal fluency. Animal Naming is a measure of semantic fluency, or the ability to produce unique words that belong to a category in one minute. COWAT-FAS is a measure of lexical fluency, requiring the participant to produce words that begin with a specific letter across three trials. The COWAT has been found to have high internal consistency $(\alpha=0.83)$ and high test-retest reliability $(\alpha=0.74)$ (Ruff, Light, Parker, \& Levin, 1996).

The Boston Naming Test (BNT) was originally published in 1978 (Kaplan et al., 1978) with 85 items and was revised to 60 items in 1983 (Kaplan et al., 1983). Shorter versions, including the 30-odd item were developed throughout the 1980s and 1990s. It is a test of confrontation naming (e.g., word finding). It presents sketches of items (e.g., harmonica, volcano, or acorn) that must be named by the participant. This task is untimed and provides different levels of cueing if the participant has trouble thinking of the correct word. It has continued to show high reliability and validity over the last few decades in clinical use (Ferraro \& Lowell, 2010). Furthermore, naming has been found to decline significantly with age (Albert, Heller, \& Milberg, 1988) and may also be used to predict more serious cognitive impairments (Marra, Silveri, \& Gainotti, 2000).

Learning and Memory. The California Verbal Learning Test (CVLT) was originally developed by Delis and colleagues (1987) and revised in 2000. It measures 
verbal learning, immediate and delayed recall, and recognition memory. A list of words is presented across five trials for immediate free recall and learning. After a delay of 2030 minutes, participants must freely recall the words. There are cued recall trials after both immediate recall and delayed recall, in which the participant is asked to provide all the words that belonged to a specific category (e.g., vegetables). Recognition memory is assessed directly after the delayed recall through a $\mathrm{Y} / \mathrm{N}$ recognition task. The CVLT has been reported to have good test-retest reliability (0.80-0.84; Woods, Delis, Scott, Kramer, \& Holdnack, 2006) and validity for verbal learning and memory (Elwood, 1995).

The revised Brief Visuospatial Memory Test (BVMT-R) is similar to the CVLT (above) and measures visual learning across three trials as well as delayed and recognition memory of visual stimuli. It was revised over a decade ago and has strong reliability for the total recall score $(0.80)$, as well as construct validity for measuring visual memory. Interrater reliability has been found to be high $(>0.90$; Benedict, Schretlen, Groninger, Dobraski, \& Shpritz, 1996).

Visual Spatial Skills. WAIS-III Block Design requires manual manipulation of visuospatial stimuli presented, with additional points for higher processing speed. The Block Design task has high internal consistency reliability (average 0.87 for adults older than 65) and loads onto a perceptual reasoning factor within a four factor model that also includes verbal comprehension, working memory, and processing speed (Wechsler et al., 2008).

The Benton Judgment of Line Orientation (Benton, Varney, \& Hamsher, 1978) requires identification of visuospatial stimuli by matching the angle of lines seen in an example figure. The test has been found to have good construct validity in measuring 
visual spatial abilities as well as high test-retest reliability $(0.90)$. The measure has been found to be correlated with other visual spatial tests, including WAIS-R Block Design $(r=0.68 ;$ see Spreen \& Strauss, 1998).

Motor dexterity. Although not a cognitive test, the Grooved Pegboard (Matthews \& Klove, 1964) test is commonly used in clinical settings and was administered to measure manual dexterity. The test requires participants to manually maneuver a metal peg, using one hand at a time, into a pegboard that contains grooves angled in different directions. This is a brief test that presents another aspect of brain functioning and was analyzed as a possible covariate to other manual and/or timed tests. It has been supported as a test of visuomotor ability, and although women have been found to be faster than men (e.g., Ruff \& Parker, 1993), this effect is smaller in older populations and can be used in many situations if it is interpreted with strong normative data.

In addition to the neuropsychological assessments, participants completed questionnaires measuring physical activity, social activity, general quality of life and physical health. The following questionnaires were chosen to obtain data on the above variables:

Mood. Geriatric Depression Scale (GDS)-15. The GDS-15 is a screening tool, used to assess for the possible presence of depression. All questions are dichotomous $(\mathrm{Y} / \mathrm{N})$ and there is a cutoff score of 5 , such that anyone scoring 5 or more points is at a risk for the presence of depressive symptoms. The GDS-15 has been found to have high internal consistency $(\alpha=0.80)$ and each of the 15 items was significantly correlated with the overall score (D’Ath, Katona, Mullan, Evans, \& Katona, 1994). 
Physical Activity Level. Community Health Activities Model Program for Seniors (CHAMPS). The CHAMPS questionnaire (Stewart, et al., 2001) is a self-report measure that asks older adults about their participation in over 40 physical activities. For each activity individuals participated in, they are asked to report on average the frequency per week with which they took part in the activity described, and on average how many hours a week they spent engaged in the activity.

Quality of Life. The Quality of Life-Alzheimer's Disease (QoL-AD) was initially designed to measure quality of life in patients with $\mathrm{AD}$ in 13 domains, and for this population has good internal consistency ( $\alpha=0.88$; Logsdon, Gibbons, McCurry, \& Teri, 1999). Each domain (including physical health, finances, mood, and family) is rated on a 4-point scale from poor to excellent. Lower scores indicate poorer quality of life. A recent study was also conducted using this same measure on non-demented community dwelling older adults, and found similar levels of internal consistency ( $\alpha=0.83$; Revell, Caskie, Willis, \& Schaie, 2009).

Social Activity Level. California Older Persons Pleasant Events Scale (COPPES). The COPPES (Rider, Gallagher-Thompson, \& Thompson, 2004) is a self-report measure including 66 items that some people find enjoyable. Individuals are asked to rate the frequency for which they participated in each activity (e.g., being with friends, shopping, listening to music) in the past month. They then rate the activity again as how much they enjoyed the activity, or how much they would have enjoyed the activity had they done it. The 66 items form five subscales that include scores for Socializing ( 8 items), Relaxing (12 items), Contemplating (9 items), Being Effective ( 9 items), and Doing ( 8 items). The current study was interested particularly in the socializing subscale as a measure of the 
frequency of social activity. The COPPES has shown good internal consistency, ranging from $\alpha=0.63-0.86$. The Socialization subscale had $\alpha=0.82$ for frequency and $\alpha=0.81$ for the pleasure rating in two separate samples (Rider, et al., 2004).

\section{Procedures}

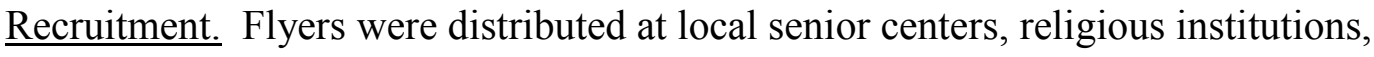
fine arts facilities, and sent out via email to local organizations (e.g., Louisville Musician's Union, Louisville VFW halls, Louisville Orchestra). Participants were also recruited from nearby metropolitan areas, including Indianapolis, IN, Lexington, KY, and Cincinnati, OH. Potential participants were initially screened through a phone interview. The interview explained the general outline of the study so that the individual understood what was expected of him/her during participation and would know what to expect from the experience. Individuals interested in participating after the more detailed explanation were asked to answer some questions to ensure that they met inclusion requirements. These questions included age, living situation, if they currently had a diagnosis of depression, or had a history any cognitive impairment (i.e., history of stroke, Parkinson's disease). Musicians were also asked if they were instrumentalists and if so, how many years of private lessons they had taken.

Evaluation. After being scheduled for testing but prior to beginning the evaluation, each participant received a summary of the study and provided written consent to participate. Participants were informed that they could decline to answer any questions that made them uncomfortable, decline to complete tasks that made them uncomfortable, or discontinue participation at any point. All participants completed a questionnaire asking about their musical experiences, including how often they listened 
to music, what kind of music they preferred, and what role music played in their lives. Musicians then answered further questions including the age at which they began playing, what instruments they played, if they were involved in any ensembles (band, orchestra, jazz band), if they took private lessons and for how long, on average the number of hours they played per week at the peak of training, if they composed or improvised, to what extent, if at all, they still participate in music activities, and current and past use of benzodiazepines for the management of performance anxiety. All participants were administered the neuropsychological testing battery, and other questionnaires measuring mood, physical activity, quality of life, level of social engagement, religious participation, and overall self-reported medical health conditions. The order of the questionnaires with the testing battery was randomized across participants so as to avoid any order biases. Each participant was assigned a subject number. The subject numbers were used on all further documents for de-identification, including entry in the computer database. After data entry, the data were cleaned and analyzed for any errors or outliers.

\section{$\underline{\text { Statistical Power and Sample Size }}$}

The study by Hanna-Pladdy and MacKay (2011) had a sample size of 70 and found significant differences between musicians and non-musicians with effect sizes that fell into the medium to large range $(0.58-0.98)$. In order to replicate this study using a case-match design, with $\beta=0.20$ and $\alpha=0.05$, and with this range of effect sizes, sample size estimates indicated that between 36 and 94 participants were necessary. The goal was to recruit 68 participants, a sample large enough to detect many differences and comparable to Hanna-Pladdy and MacKay (2011). Seventy-four people were recruited and the final sample analyses included 58 total participants, divided into subgroups of 
high-activity musicians, low-activity musicians, and non-musicians (demographics presented in Table 1). Individuals were screened out of participating for the following reasons: positive depression screen on GDS $(\mathrm{N}=1)$, history of stroke $(\mathrm{N}=2)$, diagnosis of Parkinson's disease ( $\mathrm{N}=1)$, vocalist with no prior instrumental training $(\mathrm{N}=2)$, too few years of private lessons ( $\mathrm{N}=5)$, illiteracy $(\mathrm{N}=1)$, and less than 65 years old $(\mathrm{N}=4)$. All participants who were enrolled in the study completed the evaluation.

Data Analysis. Attempts were made to match groups for education, sex, and age, within five years. ANOVAs determined if there were differences between the groups on frequency of social activity in the past month, hours of weekly self-reported physical activity, total number of self-reported health problems, and age. Chi-square analyses measured differences between the groups in education level and gender.

Hypothesis 1 \& 2: An ANCOVA was used to examine between-groups differences in the neuropsychological performances on all cognitive tests, with particular attention paid to verbal and visual memory, and executive function, while controlling for covariates. Hypothesis 3: Bivariate correlations were used to examine the relationships between music training variables, including age at which individual began playing, number of years in lessons, current number of weekly hours practicing, number of weekly hours practicing at peak training, and all neuropsychological test scores.

Hypothesis 4: Hierarchical regression analyses tested what variables (physical activity, social activity, age, education, general health, or musical training) were unique and significant predictors of scores on cognitive scores in both musicians and non-musicians. 


\section{RESULTS}

Demographics per group (high-activity, low-activity, and non-musician) are presented in Table 1. Attempts were made to match non-musicians to musicians on the variables of age, education level, and gender; however a match was not perfectly achieved and non-musicians were over-sampled. The samples were not significantly different in terms of age $(F(2,55)=1.51, p>0.05)$, self-reported number of hours per week of physical activity $(F(2,50)=1.00, p>0.05)$, self-reported frequency of social engagement $(F(2,52)=0.42, p>0.05)$, or self-reported total number of health problems $(F(2,51)=0.90, p>0.05)$. Chi-square analyses determined that the groups were statistically equivalent in terms of gender $\left(\chi^{2}(2)=3.69, p>0.05\right)$. The groups showed a similar number of left- and right-handedness $(p>0.05)$, including one left-handed individual in the non-musician group, none in the low-activity musician group, and three in the high-activity musician group, which was not significant. The groups differed in terms of education level $(F(1,55)=6.64, p<0.05)$. Post-hoc comparisons revealed that high-activity musicians had significantly more education compared to non-musicians ( $p=$ 0.04). There was a linear trend; however, differences in education level were nonsignificant between non-musicians and low-activity musicians, and between low-activity musicians and high-activity musicians $(p>0.05)$. Due to the differences in education, education was statistically controlled for in all subsequent analyses. Details of the 
musician sample, including instruments represented, and information on composing and improvising, are presented in Table 2 . Categories in Table 2 are not mutually exclusive.

Table 1

Demographics by Musician Training: N (\%)

\begin{tabular}{|c|c|c|c|}
\hline$\underline{\text { Demographic Variable }}$ & $\frac{\text { High Musician }}{(\mathrm{N}=23)}$ & $\frac{\text { Low Musician }}{(\mathrm{N}=22)}$ & $\frac{\text { Non-Musician }}{(\mathrm{N}=13)}$ \\
\hline \multicolumn{4}{|l|}{ Gender } \\
\hline Male & $13(56.5)$ & $14(63.6)$ & $4(30.8)$ \\
\hline Female & $10(43.5)$ & $8(36.4)$ & $9(69.2)$ \\
\hline Age & $\begin{array}{l}65-88 ; M=71.26 \\
(\mathrm{SD}=6.53)\end{array}$ & $\begin{array}{l}66-86 ; M=73.86 \\
(\mathrm{SD}=5.30)\end{array}$ & $\begin{array}{l}67-87 ; M=74.15 \\
(\mathrm{SD}=5.35)\end{array}$ \\
\hline \multicolumn{4}{|c|}{ (ס) - } \\
\hline$<12^{\text {th }}$ grade & $1(4.3)$ & $0(0)$ & $1(7.7)$ \\
\hline High School & $0(0)$ & $2(9.1)$ & $2(15.4)$ \\
\hline Some College & $1(4.3)$ & $3(13.6)$ & $3(23.1)$ \\
\hline College Graduate & $6(26.1)$ & $8(36.4)$ & $3(23.1)$ \\
\hline Graduate Training & $15(65.2)$ & $9(40.9)$ & $4(30.8)$ \\
\hline \multicolumn{4}{|l|}{ Marital Status } \\
\hline Single & $1(435)$ & $1(4.5)$ & $0(0)$ \\
\hline Divorced/Separated & $7(30.4)$ & $3(13.6)$ & $3(23.1)$ \\
\hline Widow(er) & $4(17.4)$ & $1(4.5)$ & $2(15.4)$ \\
\hline Married & $11(47.8)$ & $17(77.3)$ & $8(61.5)$ \\
\hline \multicolumn{4}{|l|}{ Employment Status } \\
\hline Full Time & $4(17.4)$ & $0(0)$ & $0(0)$ \\
\hline Part Time & $5(21.7)$ & $2(9.1)$ & $1(7.7)$ \\
\hline Retired & $14(60.9)$ & $20(90.9)$ & $11(84.6)$ \\
\hline Unemployed & $0(0)$ & $0(0)$ & $1(7.7)$ \\
\hline \multicolumn{4}{|l|}{ Living Arrangements } \\
\hline Alone & $8(34.8)$ & $5(22.7)$ & $4(30.8)$ \\
\hline With Spouse/Partner & $15(65.2)$ & $17(77.3)$ & $9(69.2)$ \\
\hline Age Began Playing & $\begin{array}{l}3-17 ; \mathrm{M}=7.74 \\
(\mathrm{SD}=2.91)\end{array}$ & $\begin{array}{l}2-14 ; M=9.26 \\
(\mathrm{SD}=3.10)\end{array}$ & N/A \\
\hline Years in Lessons & $\begin{array}{l}10-20 ; M=13.74 \\
(\mathrm{SD}=3.72)\end{array}$ & $\begin{array}{l}0-8 ; \mathrm{M}=3.36 \\
(\mathrm{SD}=3.12)\end{array}$ & $\mathrm{N} / \mathrm{A}$ \\
\hline $\begin{array}{l}\text { Currently Playing (hrs per } \\
\text { week) }\end{array}$ & $\begin{array}{l}0-30 ; \mathrm{M}=9.00 \\
(\mathrm{SD}=8.12)\end{array}$ & $\begin{array}{l}0-10 ; M=3.15 \\
(\mathrm{SD}=3.27)\end{array}$ & N/A \\
\hline
\end{tabular}


Table 2

Demographics of Musician Sample

\begin{tabular}{|l|c|}
\hline Musician Demographic & $\underline{\mathrm{N}=(\%)}$ \\
\hline Instrument & \\
\hline Strings & $14(29.5)$ \\
\hline Piano & $24(54.5)$ \\
\hline Wind & $12(27.3)$ \\
\hline Brass & $15(34.1)$ \\
\hline Percussion & $6(13.6)$ \\
\hline Ensemble Participation & $36(81.8)$ \\
\hline Composer & $13(29.5)$ \\
\hline Improviser & $19(43.2)$ \\
\hline Currently Playing & $32(72.7)$ \\
\hline
\end{tabular}

Missing data were either excluded pairwise or means were substituted (described below). Three participants' scores on frequency of social activity and four participants' total health conditions could not be calculated due to missing information. At least 20 participants were missing one to two variables from the CHAMPS physical activity questionnaire, leading to missing variables about the total number of times they engaged in activities. However, only eight participants were missing information about the number of hours per week they engaged in physical activities, so the "number of hours" variable was used to calculate total physical activity, rather than frequency of engaging in weekly activities. Of the neuropsychological tests, eight participants did not complete some part of the visual memory test (BVMT-R), one participant did not complete the fourth trial of Color Word Interference (CW4), and two participants did not complete WAIS-III Block Design.

$\underline{\text { Hypotheses } 1 \& 2}$ 
To test the hypotheses that significant differences exist between musicians and non-musicians after controlling for the possible covariates (i.e., education, physical and social activity, and overall health), an ANCOVA analyzed scores on all neuropsychological tests, including executive function, attention/working-memory, language, verbal and visual memory, visual-spatial ability, and motor function (see Table 3). Missing data were excluded pairwise. Levene's Test of Equality of Error Variances was non-significant ( $p>0.05$ for any neuropsychological test).

Table 3

$\underline{\text { Raw Score Means (Standard Deviations) of Cognitive Scores }}$

\begin{tabular}{|l|c|c|c|}
\hline Cognitive Test & High-Musician & Low-Musician & Non-Musician \\
\hline $\begin{array}{l}\text { CVLT-Total } \\
\text { Immediate }\end{array}$ & $51.35(9.74)$ & $47.91(7.48)$ & $51.23(10.73)$ \\
\hline CVLT-SDFR & $10.61(2.93)$ & $9.55(2.48)$ & $9.92(3.48)$ \\
\hline CVLT-SDCR & $12.04(2.64)$ & $11.18(2.15)$ & $11.85(2.51)$ \\
\hline CVLT-LDFR & $11.00(4.02)$ & $10.14(2.34)$ & $10.69(3.22)$ \\
\hline CVLT-LDCR & $12.13(2.78)$ & $11.18(1.82)$ & $11.46(2.50)$ \\
\hline BVMT-R-Delay & $9.04(1.77)$ & $8.59(2.44)$ & $8.54(2.07)$ \\
\hline RFFT & $80.57(22.56)$ & $70.45(18.96)$ & $80.00(21.31)$ \\
\hline Digit Span & $27.43(4.85)$ & $27.50(3.79)$ & $26.69(4.82)$ \\
\hline Animals & $22.61(5.97)$ & $22.41(5.77)$ & $21.69(4.64)$ \\
\hline COWA-FAS & $45.35(10.48)$ & $41.86(10.64)$ & $42.77(12.03)$ \\
\hline Trails A (sec) & $34.48(11.20)$ & $34.68(11.79)$ & $35.00(8.50)$ \\
\hline Trails B (sec) & $84.83(28.45)$ & $82.77(38.79)$ & $94.77(30.07)$ \\
\hline Trails B-A & $50.34(23.80)$ & $48.55(37.51)$ & $59.77(28.92)$ \\
\hline$*$ CW3 (sec) & $61.57(18.27)$ & $64.77(13.61)$ & $71.31(16.22)$ \\
\hline **WW (sec) & $62.18(12.23)$ & $68.86(18.39)$ & $79.85(16.41)$ \\
\hline **BNT & $28.74(1.45)$ & $28.95(1.09)$ & $26.54(2.07)$ \\
\hline$*$ BD & $39.17(10.84)$ & $33.86(8.01)$ & $30.00(6.90)$ \\
\hline *JOLO & $26.37(2.68)$ & $24.95(3.79)$ & $22.77(3.70)$ \\
\hline Peg-Dom (sec) & $94.59(26.92)$ & $100.41(24.85)$ & $94.62(21.43)$ \\
\hline $\begin{array}{l}\text { Peg-NonDom } \\
\text { (sec) }\end{array}$ & $109.41(41.96)$ & $112.77(28.79)$ & $107.77(16.56)$ \\
\hline Notes: CVLT Cal & & \\
\hline
\end{tabular}

Notes: CVLT=California Verbal Learning Test-II; BVMT=Brief Visual Memory Test; RFFT=Ruff Figural Fluency Test; COWA=Controlled Oral Word Association; $\mathrm{CW}=$ Color Word Interference; $\mathrm{BNT}=$ Boston Naming Test; $\mathrm{BD}=\mathrm{Block}$ Design; $\mathrm{JOLO}=$ Judgment of Line Orientation. 
$*$ denotes $p<0.05, * *$ denotes $p<0.01$ for ANCOVA F-test

Executive Function. In the domain of executive function, between-subjects effects were observed on D-KEFS Color-Word Interference Trial 3 (CW3) $(F(2,45)=$ 4.38, $p<0.02$; partial $\left.\eta^{2}=0.06\right)$ and Color-Word Interference Trial $4(\mathrm{CW} 4)(F(2,56)=$ 4.22, $p<0.05$; partial $\left.\eta^{2}=0.138\right)$. There was a significant linear trend for CW4 $(F(1,54)$ $=9.81, p<0.01$ ), indicating that as music training increased, performance on CW4 increased. Simple contrasts found significant differences between non-musicians and high-activity musicians $(p<0.01)$ on CW4, such that the high-activity musicians showed the best performance (high-activity musicians $M=62.4$ seconds, $S E=3.5, \mathrm{CI}_{95}=55.44$ 69.36; low-activity musicians $M=68.85$ seconds, $S E=3.40, \mathrm{CI}_{95}=62.04-75.67$; nonmusicians $M=79.50$ seconds, $S E=4.57, \mathrm{CI}_{95}=70.33$ - 88.66). However the difference between subgroups of musicians (low-activity and high-activity) was non-significant.

There were no observed effects of musician group membership on another test of executive function (Trails B); however, performance on Trails B was correlated with another test of set-switching (CW3, $r=0.41, p<0.01)$ and with an executive task of set switching and inhibition (CW4, $r=0.26, p=0.05)$.

Attention and Working Memory. There were no observed effects of musician group membership on multiple tests of attention/working-memory (Digit Span, Ruff Figural Fluency Test).

Language. Between-subjects effects were observed for a test of confrontation naming (Boston Naming Test, BNT; $F(2,57)=12.29, p<0.001 ;$ partial $\eta^{2}=0.31$ ). Simple contrasts found that there were significant differences between musician groups and non-musicians $(p<0.001)$. High- and low-activity musicians showed better 
performance than non-musicians (high-activity musicians $M=28.80$ raw score, $S E=$ $0.32, \mathrm{CI}_{95}=28.16-29.44$; low-activity musicians $M=28.95$ raw score, $S E=0.32, \mathrm{CI}_{95}=$ 28.31 - 29.59; non-musicians $M=26.45$ raw score, $S E=0.43, \mathrm{CI}_{95}=25.58$ - 27.31). Scores between subgroups of musicians did not differ statistically.

There was no observed effect of musician group membership on tests of language fluency (COWA and Animals).

Memory. There were no observed effects of musician group membership on tests of verbal or visual memory (CVLT-ii, and BVMT-R).

Visual Spatial Ability. Between-subjects effects were observed on both Block Design $\left(\mathrm{BD} ; F(2,55)=3.27, p<0.05 ;\right.$ partial $\left.\eta^{2}=0.11\right)$ and Judgment of Line Orientation (JOLO; $F(2,57)=3.61, p<0.05$; partial $\left.\eta^{2}=0.12\right)$. Simple contrasts found significant differences between high-activity musicians and non-musicians $(p<0.05)$ on JOLO, where high-activity musicians showed better performance (high-activity musicians $M=26.37$ raw score, $S E=0.72, \mathrm{CI}_{95}=24.94-27.81$; low-activity musicians $M=24.97$ raw score, $S E=0.71, \mathrm{CI}_{95}=23.54-26.40$; non-musicians $M=23.08$ raw score, $\left.S E=0.96, \mathrm{CI}_{95}=21.15-25.01\right)$. There were no significant differences between subgroups of musicians. Simple contrasts found significant differences between highactivity musicians and non-musicians $(p<0.05)$ on $\mathrm{BD}$, where high-activity musicians performed the best, followed by low-activity musicians, and then non-musicians (highactivity musicians $M=38.94$ raw score, $S E=1.96, \mathrm{CI}_{95}=35.02-42.87$; low-activity musicians $M=33.90$ raw score, $S E=1.96, \mathrm{CI}_{95}=29.97-37.83$; non-musicians $M=$ 30.47 raw score, $\left.S E=2.86, \mathrm{CI}_{95}=24.66-36.15\right)$. 
Motor Dexterity. There were no observed effects of musician group membership on tests of motor functioning (Grooved Pegboard).

$\underline{\text { Hypothesis } 3}$

It was hypothesized that there would be significant correlations between music training variables, including age of beginning lessons, years in private lessons, current weekly number of hours practicing, weekly hours practicing at the peak of music training, and cognitive test scores. Bivariate correlations analyzed the relationship between different factors of musical training and cognitive functioning. Music training variables listed above were included in the analyses as well as all neuropsychological test data. Missing data were excluded pairwise due to the small number of missing data points.

Most music training variables were significantly correlated with each other (see Table 4). The number of years a musician was enrolled in lessons was significantly and positive correlated with current number of hours of week they played both at the peak of training $(r=0.63, p<0.01)$ and currently $(r=0.43, p<0.01)$, as well as negatively with the age at which they began playing $(r=-0.39, p<0.01)$. Prior practicing frequency and current practice were significantly correlated $(r=0.47, p<0.01)$. The age at which a musician began playing was not significantly correlated with the number of hours practiced during peak musical training $(r=-0.004, p>0.05)$ or currently $(r=0.26, p>$ 0.05). Number of years in lessons was significantly correlated with education level $(r=$ $0.37, p=0.01)$. 
Table 4

Correlations of Music Training Variables

\begin{tabular}{|c|c|c|c|c|c|}
\hline $\begin{array}{l}\frac{\text { Music }}{\text { Training }} \\
\text { Variables }\end{array}$ & Age Began & $\frac{\text { Yrs in }}{\underline{\text { Lessons }}}$ & $\begin{array}{l}\text { Hrs Practice/ } \\
\underline{\text { Wk (Prior) }}\end{array}$ & $\begin{array}{l}\text { Hrs Practice/ } \\
\text { Wk (Current) }\end{array}$ & Education \\
\hline Age Began & 1 & & & & \\
\hline $\begin{array}{l}\text { Years in } \\
\text { Lessons }\end{array}$ & $-0.39 * *$ & 1 & & & \\
\hline $\begin{array}{l}\text { Hrs Practice/ } \\
\text { Wk (Prior) }\end{array}$ & -0.00 & $0.63 * *$ & 1 & & \\
\hline $\begin{array}{l}\text { Hrs Practice/ } \\
\text { Wk (Current) }\end{array}$ & 0.26 & $0.43 * *$ & $0.47 * *$ & 1 & \\
\hline Education & -0.15 & $0.37 *$ & 0.28 & 0.10 & 1 \\
\hline
\end{tabular}

$*$ denotes $p<0.05, * *$ denotes $p<0.01$

Bivariate correlations of the musician sample between music training variables and performance on neuropsychological tests are presented in Table 5. The age at which musicians began playing was not correlated with scores on any neuropsychological tests (all tests $p>0.05$ ). Similarly, the current number of weekly hours musicians were playing was not correlated with scores on any neuropsychological tests (all tests $p>0.05$ ). The number of years musicians were enrolled in private lessons was significantly and positively correlated with scores of verbal memory, including immediate recall $(r=0.31$, $p<0.05)$, short delay free recall $(r=0.33, p<0.05)$, and long delay cued recall $(r=0.33$, $p<0.05)$. There were also trends for positive correlations of number of years enrolled in lessons with short delay cued recall $(r=0.27, p=0.06)$, long delay free recall $(\mathrm{r}=0.274$ $p=0.08)$, and recognition discrimination $(r=0.23, p=0.09)$. Prior number of hours practiced per week (e.g., the number of hours an individual practiced per week during peak music training) was significantly and positively correlated with verbal fluency $(\mathrm{COWA} ; r=0.32, p<0.05)$ and visual spatial ability $(\mathrm{BD} ; r=0.32, p<0.05)$. 
Table 5

Bivariate Correlations of Musicians' $(\mathrm{N}=41)$ Music Training and Cognitive Scores

\begin{tabular}{|c|c|c|c|c|}
\hline$\underline{\text { Cognitive Test }}$ & $\underline{\text { Age Began }}$ & $\frac{\text { Yrs in }}{\text { Lessons }}$ & $\frac{\text { Hrs/Week }}{\text { (prior) }}$ & $\frac{\text { Hrs/Wk }}{\text { (Current) }}$ \\
\hline $\begin{array}{l}\text { CVLT } \\
\text { Immediate } \\
\text { Recall }\end{array}$ & -0.05 & $0.34^{*}$ & 0.26 & -0.12 \\
\hline $\begin{array}{l}\text { CVLT: Short } \\
\text { Delay Free } \\
\text { Recall }\end{array}$ & -0.00 & $0.33^{*}$ & 0.23 & -0.05 \\
\hline $\begin{array}{l}\text { CVLT: Short } \\
\text { Delay Cue } \\
\text { Recall }\end{array}$ & 0.01 & 0.27 & 0.13 & -0.11 \\
\hline $\begin{array}{l}\text { CVLT: Long } \\
\text { Delay Free } \\
\text { Recall }\end{array}$ & 0.03 & 0.24 & 0.21 & -0.21 \\
\hline $\begin{array}{l}\text { CVLT: Long } \\
\text { Delay Cue } \\
\text { Recall }\end{array}$ & -0.02 & $0.29 *$ & 0.27 & 0.05 \\
\hline $\begin{array}{l}\text { CVLT: Recog. } \\
\text { Discrimination }\end{array}$ & -0.02 & 0.23 & -0.04 & -0.08 \\
\hline CW1 & -0.06 & -0.02 & -0.22 & 0.06 \\
\hline CW2 & -0.13 & -0.10 & -0.22 & 0.03 \\
\hline CW3 & -0.02 & -0.16 & -0.26 & -0.11 \\
\hline CW4 & -0.15 & -0.18 & -0.16 & -0.16 \\
\hline $\begin{array}{l}\text { BVMT: } \\
\text { Delayed } \\
\text { Recall }\end{array}$ & 0.01 & 0.20 & 0.19 & -0.01 \\
\hline Digit Span & 0.02 & -0.15 & 0.06 & -0.24 \\
\hline RFFT & 0.04 & 0.26 & 0.21 & -0.12 \\
\hline COWA-FAS & -0.09 & 0.13 & $0.32 *$ & 0.05 \\
\hline $\begin{array}{l}\text { Animal } \\
\text { Naming }\end{array}$ & -0.11 & 0.12 & 0.23 & -0.13 \\
\hline $\begin{array}{l}\text { Pegboard- } \\
\text { Dominant }\end{array}$ & -0.12 & -0.11 & -0.05 & -0.20 \\
\hline $\begin{array}{l}\text { Pegboard- } \\
\text { NonDominant }\end{array}$ & -0.07 & 0.02 & -0.01 & -0.09 \\
\hline $\mathrm{BNT}$ & 0.21 & -0.03 & -0.08 & 0.00 \\
\hline JOLO & -0.02 & 0.17 & 0.27 & 0.14 \\
\hline $\mathrm{BD}$ & -0.10 & 0.19 & $0.32 *$ & 0.08 \\
\hline Trails A & -0.14 & -0.11 & -0.08 & -0.04 \\
\hline Trails B & -0.15 & 0.16 & -0.06 & 0.08 \\
\hline
\end{tabular}


* denotes $p<0.05$

Hypothesis 4

The final hypothesis was that age would be the strongest predictor of test scores, but that other variables, including education, physical and social activity, and music training would also significantly predict neuropsychological performance. Several hierarchical regression analyses were conducted with neuropsychological tests as the dependent variables and age, education, physical activity, social activity, overall health, and music training as predictors as independent variables (see Table 6).

Table 6

Beta Weights from Block 4 Regressions Predicting Cognitive Test Performance

\begin{tabular}{|c|c|c|c|c|c|c|c|c|c|c|}
\hline $\begin{array}{l}\text { Cog. } \\
\text { Test }\end{array}$ & Age & $\frac{\text { Grad }}{\underline{\text { Sch. }}}$ & $\frac{\text { Bach }}{\text { Deg. }}$ & $\begin{array}{l}\text { Some } \\
\text { Coll. }\end{array}$ & $\underline{\mathrm{HS}}$ & $\begin{array}{l}\text { Phys. } \\
\text { Act. }\end{array}$ & $\begin{array}{l}\text { Soc. } \\
\text { Act. }\end{array}$ & $\frac{\text { Healt }}{\underline{\mathrm{h}}}$ & $\frac{\text { High }}{\text { Mus }}$ & $\underline{\text { Low }}$ \\
\hline $\begin{array}{l}\overline{\text { CVL }} \\
\mathrm{T} \\
\text { Total }\end{array}$ & -.27 & 1.36 & .12 & 1.12 & .14 & $\frac{1.15}{1.15}$ & -.10 & -.10 & -.14 & -.21 \\
\hline $\begin{array}{l}\text { CVL } \\
\mathrm{T} \\
\text { SDF } \\
\mathrm{R} \\
\end{array}$ & $-.34^{*}$ & .19 & .08 & -.01 & .14 & .03 & -.05 & -.15 & -.02 & -.11 \\
\hline $\begin{array}{l}\text { CVL } \\
\mathrm{T} \\
\mathrm{LDF} \\
\mathrm{R} \\
\end{array}$ & $-.44^{*}$ & -.10 & -.08 & -.17 & .07 & .11 & .06 & -.20 & -.12 & -.13 \\
\hline $\begin{array}{l}\text { BVM } \\
\text { T } \\
\text { Dela } \\
\text { y }\end{array}$ & $-.46^{*}$ & -.08 & -.12 & -.26 & .05 & -.12 & -.15 & .04 & .03 & .02 \\
\hline $\begin{array}{l}\text { Trail } \\
\text { s A }\end{array}$ & $.43^{* *}$ & .18 & .02 & -.05 & -.04 & .13 & .04 & .18 & .01 & \begin{tabular}{|l|} 
\\
\end{tabular} \\
\hline $\begin{array}{l}\text { Trail } \\
\text { s B }\end{array}$ & .18 & -.11 & -.13 & .07 & -.26 & .04 & .25 & .17 & -.13 & -.16 \\
\hline CW1 & .03 & -.43 & -.29 & -.05 & -.19 & .17 & -.11 & .11 & .01 & -.12 \\
\hline CW2 & .06 & -.07 & .20 & .15 & .01 & .01 & -.08 & .01 & -.32 & -.38 \\
\hline CW3 & .10 & .17 & .10 & .16 & .15 & .11 & -.05 & $.40^{* *}$ & -.16 & -.11 \\
\hline CW4 & .27 & -.02 & .18 & -.03 & .00 & .02 & .02 & -.17 & $\begin{array}{c}- \\
.50^{* *}\end{array}$ & $-.37^{*}$ \\
\hline
\end{tabular}




\begin{tabular}{|l|c|c|c|c|c|c|c|c|c|c|}
\hline BNT & $-.24 *$ & .05 & .06 & -.10 & .28 & .06 & -.10 & -.02 & $.60^{* *}$ & $.68^{* *}$ \\
\hline $\begin{array}{l}\text { Anim } \\
\text { al }\end{array}$ & -.13 & .12 & .09 & -.01 & .05 & .13 & .01 & -.21 & -.05 & .00 \\
\hline $\begin{array}{l}\text { CO } \\
\text { WA }\end{array}$ & -.02 & -.08 & -.17 & -.09 & .08 & .09 & -.04 & -.24 & .09 & -.05 \\
\hline BD & -.03 & .55 & .57 & .17 & .39 & .18 & -.09 & $-.30^{*}$ & .31 & .05 \\
\hline $\begin{array}{l}\text { JOL } \\
\text { O }\end{array}$ & .15 & .48 & .49 & .44 & -.08 & .13 & -.23 & -.10 & $.48^{* *}$ & .24 \\
\hline $\begin{array}{l}\text { Digit } \\
\text { Span }\end{array}$ & -.28 & .04 & -.02 & -.13 & .29 & .02 & .02 & -.04 & .04 & .51 \\
\hline $\begin{array}{l}\text { Peg- } \\
\text { Dom }\end{array}$ & $.57 * *$ & .56 & .42 & .23 & .16 & .10 & -.01 & $.28^{*}$ & .10 & .11 \\
\hline $\begin{array}{l}\text { Peg- } \\
\text { Non } \\
\text { Dom }\end{array}$ & $.28 *$ & .24 & .16 & .04 & .00 & .14 & -.04 & $.42^{* *}$ & .10 & .12 \\
\hline
\end{tabular}

Notes: Block 1 = Constant + Age; Block 2 = add education level; Block 3 = add total physical activity, total social activity, total self-reported health problems; Block $4=$ add music training

$* p<0.05, * * p<0.01$

Because not all variables were continuous, and categorical variables had more than two categories, dummy codes were created for levels of music training and education level. Excluding the number of cases pairwise would have reduced the total sample from 58 to 39 , including frequency of social activity $(\mathrm{N}=4)$, total health conditions $(\mathrm{N}=4)$, number of weekly hours of physical activity $(\mathrm{N}=8)$, visual memory test $(\mathrm{N}=8)$, color-word interference trial $4(\mathrm{~N}=1)$, block design $(\mathrm{N}=2)$, and grooved pegboard $(\mathrm{N}=1)$. In an effort to include more participants' data into the analyses, means were substituted for missing variables. Blocks were entered in this order: Block $1=$ age, Block 2 = education dummy codes, Block 3 = frequency of social activity, physical activity, number of self-reported health conditions, Block $4=$ music training dummy codes. Models refer to each step of block entry. All neuropsychological tests were analyzed, including tests of memory (CVLT, BVMT-R), working memory and attention (Digit Span, RFFT, Trails A), executive function (Trails B, CW 1-4), language (Animals, 
COWA, BNT), motor function (Grooved Pegboard dominant and non-dominant hands), and visual spatial ability (BD, JOLO).

Executive Function. Models were non-significant for predicting one test of executive function (Trails B, $p>0.05$ ). Although non-significant, age accounted for $3.0 \%$ of the variance in scores, education accounted for $7.7 \%$, health and activity accounted for $8.8 \%$, and music training accounted for $1.5 \%$ of the variance on scores of Trails B.

For scores on Color Word Interference 1 and 2 (CW1; CW2), no models were significant $(\mathrm{CW} 1: F(10,57)=0.70, p>0.05$; CW2: $F(10,57)=1.12, p>0.05)$. None of the models were significant for predicting scores on Color Word Interference Trial 3 $(\mathrm{CW} 3 ;(F(10,57)=1.437, p>0,05)$; however, there was a significant $\mathrm{F}$ change $(p<$ 0.05) for Model 3, which included age, education, and health and activities. Participant's total number of self-reported health conditions was the most significant predictor of scores on $\mathrm{CW} 3(\mathrm{~B}=6.06, \mathrm{SE}=1.85, t=3.27, p<0.01)$. For $\mathrm{CW}$, age accounted for $2.6 \%$, education accounted for $1.5 \%$, health and activity accounted for $18.2 \%$, and music training accounted for $1.2 \%$ of the variance of scores.

Scores on Color Word Interference Trial 4 (CW4) were best predicted by age $(F(1$, $57)=4.66, p<0.05)$. There was, however, a significant $\mathrm{F}$ change when music training level was included in the model (Model 4) $(p<0.05)$. Within Model 4, age accounted for $7.7 \%$, education accounted for $4.9 \%$, activities and health accounted for $0.9 \%$, and music training level accounted for $12.3 \%$ of the variance in scores on CW4. When music training was added to the model, age became a non-significant predictor. Both levels of music training (high and low) predicted scores on CW4 (High musicians: $\mathrm{B}=-16.98, \mathrm{SE}$ $=6.21, t=-2.73, p<0.01$; low musician: $\mathrm{B}=-12.80, \mathrm{SE}=5.84, t=-2.19, p<0.05)$. 
Attention and Working Memory. Age was the most significant predictor $(\mathrm{B}=$ $0.77, \mathrm{SE}=0.24, t=-3.28, p<0.01)$ of Trails $\mathrm{A}$, a test of attention and visual tracking $(F(1,57)=12.48, p<0.01)$. Education and activities and health were also significant predictors of scores on Trails A (Model 3: $F(8,57)=2.56, p<0.05)$; however, the $F$ change statistic was non-significant after the first model $(p>0.05)$. After all variables were entered, age accounted for $18.2 \%$ of the variance, education accounted for $6.6 \%$, health and activities accounted for $4.6 \%$ and music training accounted for $0 \%$ of the variance in scores on Trails A.

On another test of processing speed and non-verbal fluency (Ruff Figural Fluency Test; RFFT), age was again the most significant predictor $(F(1,57)=13.44, p=0.001$; B $=-1.55, \mathrm{SE}=0.42, t=-3.67, p=0.001)$. Age accounted for $19.4 \%$ of the variance, education accounted for $7.8 \%$, health and activities accounted for $1.1 \%$ and music training accounted for $2.2 \%$ of the variance in scores on RFFT.

No significant models emerged for predicting performance on a test of simple and complex auditory attention (Digit Span). With all variables entered into the model, age accounted for $5.7 \%$ of the variance, education accounted for $10.8 \%$, health and activities accounted for $0.3 \%$ and music training accounted for $0.5 \%$ of the variance in scores on Digit Span.

Language. Models were non-significant for predicting scores on tests of verbal fluency (COWA-FAS, $p>0.05$, and Animal Naming, $p>0.05$ ). Age accounted for 3.3\%, education accounted for $0.4 \%$, health and activity accounted for $5.6 \%$ and music training accounted for $0.2 \%$ of the variance in scores on Animal Naming. Age accounted for $0.6 \%$, education accounted for $4.2 \%$, health and activity accounted for $6.1 \%$, and music 
training accounted for $1.3 \%$ of the variance for scores on a lexical fluency task (COWAFAS).

Regressions predicting scores on confrontation naming (BNT) found that both high- and low-activity music training levels were the best and most significant predictor $(F(10,57)=3.82, p=0.001$; high-activity: $\mathrm{B}=2.31, \mathrm{SE}=0.56, t=3.79, p<0.001$; lowactivity: $\mathrm{B}=2.44, \mathrm{SE}=0.68, t=4.61, p<0.001)$. After music training was added to the model, age became non-significant as a predictor. Age accounted for $7.8 \%$, education accounted for $8.8 \%$, health and activities accounted for $2.3 \%$ and music training accounted for $26.3 \%$ of the variance in scores on the BNT. The percentage of variance accounted for in confrontation naming by music training was substantial, particularly because many other variables have been controlled.

Memory. Age was the best predictor of verbal memory (CVLT), including immediate learning $(F(1,57)=5.90, p=0.02)$, short delay $(F(1,57)=8.08, p<0.01)$ and long delayed free recall $(F(1,57)=15.57, p<0.001)$. Age accounted for $9.5 \%, 12.6 \%$, and $21.8 \%$ of the variance on these verbal memory trials, respectively. When education was added to the model, it accounted for an additional $5.9 \%, 2.7 \%$, and $2.3 \%$ of the variance, respectively. The variables of overall number of health conditions, and physical and social activity levels, accounted for an additional $2.9 \%, 2.0 \%$, and $4.6 \%$ of variance. When music training was added to the model, it accounted for an additional $2.4 \%, 0.1 \%, 1.0 \%$ of the variance, respectively. For immediate memory (CVLT Total Score), after all variables were entered into the model (Model 4), age became nonsignificant as a predictor $(p=0.06)$ 
Similarly for visual memory, age was the best predictor of scores on the BVMT-R delayed recall $(F(1,57)=9.97, p<0.01)$. Age accounted for $15.1 \%$ of the variance in visual memory scores. Education accounted for an additional $7.5 \%$, health and activity accounted for $3.5 \%$, and music training level accounted for $0 \%$ of the variance in visual memory scores.

Visual Spatial Ability. Model 4 for predicting scores on visual spatial ability (BD and JOLO) was significant (BD: $F(10,57)=2.07, p<0.05$; JOLO: $F(10,57)=2.75, p<$ 0.01). For BD, age accounted for $3.7 \%$, education accounted for $7.2 \%$, health and activities accounted for $13.4 \%$ and music training accounted for $6.3 \%$ of the variation in scores on $\mathrm{BD}$. When all variables were entered, number of health conditions was the most significant predictor of scores $(\mathrm{B}=-2.47, \mathrm{SE}=1.06, t=-2.32, p<0.05)$. For JOLO, age accounted for $.02 \%$, education accounted for $19.5 \%$, health and activities accounted for $13.9 \%$, and music training accounted for $23.5 \%$ of the variance in scores. With all variables entered into the regression, membership in the group of high-activity musicians was the most significant predictor $(\mathrm{B}=3.50, \mathrm{SE}=1.23, t=2.83, p<0.01)$.

Motor Function. Motor dexterity (Grooved Pegboard) scores for both dominant and non-dominant hands were best predicted by age (dominant hand: $F(1,57)=26.26, p$ $<0.001 ; \mathrm{B}=2.35, \mathrm{SE}=0.46, t=5.15, p<0.001 ;$ non-dominant hand: $F(1,57)=5.46, p$ $<0.05 ; \mathrm{B}=1.51, \mathrm{SE}=0.68, t=2.22, p<0.05)$ and self-reported health conditions (dominant hand: $F(8,57)=5.94, p<0.001 ; \mathrm{B}=5.48, \mathrm{SE}=2.25, t=2.44, p<0.05$; nondominant hand: $F(8,57)=3.03, p<0.01 ; \mathrm{B}=11.22, \mathrm{SE}=3.36, t=3.34, p<0.01)$. For the dominant and non-dominant hands, respectively, age accounted for $31.9 \%$ and $8.9 \%$, 
education accounted for $10.4 \%$ and $7.5 \%$, health and activities accounted for $6.9 \%$ and $16.7 \%$, and music training accounted for $.01 \%$ and $.01 \%$ of the variance in scores.

\section{$\underline{\text { Additional Analyses }}$}

Although not initially proposed, in order to maintain consistency with and contribute to expansion of the literature, further hierarchical regression analyses were conducted using only the musician subgroup with current age, age enrolled in lessons, years in lessons, and current number of hours per week spent playing the instrument as predictors for scores on all neuropsychological tests (see Table 7). Prior studies failed to control for social activity level or overall health, controlling only for education and physical activity. The results below were found after controlling for all of the variables mentioned above. Blocks were entered in this order: Block 1: Age; Block $2=$ Age Began taking lessons; Block 3 = years in lessons; Block 4 = current number of hours per week playing.

Table 7

Beta Weights from Block 4 Regressions Predicting Musicians' Cognitive Test Performance

\begin{tabular}{|c|c|c|c|c|}
\hline Cognitive Test & Current Age & Age Began & $\frac{\text { Years in }}{\text { Lessons }}$ & $\begin{array}{l}\text { Current } \\
\underline{\mathrm{Hrs} / \mathrm{Wk}}\end{array}$ \\
\hline CVLT Total & -.06 & .28 & $.59 * *$ & $-.43 *$ \\
\hline CVLT SDFR & -.07 & .28 & $.55^{* *}$ & $-.35^{*}$ \\
\hline CVLT LDFR & -.29 & .26 & $.43 * *$ & $-.47 *$ \\
\hline $\begin{array}{l}\text { BVMT } \\
\text { Delayed }\end{array}$ & -.21 & .11 & .25 & -.15 \\
\hline Trails A & $.52 * *$ & -.04 & .06 & .02 \\
\hline Trails B & .18 & -.07 & .02 & -.02 \\
\hline COWA & -.09 & -.09 & .07 & .06 \\
\hline Animals & -.14 & -.03 & .16 & -.18 \\
\hline CW3 & .17 & -.03 & -.12 & -.02 \\
\hline CW4 & .15 & -.20 & -.19 & -.00 \\
\hline BNT & -.29 & .07 & -.08 & -.02 \\
\hline $\mathrm{BD}$ & -.18 & -.11 & .07 & .07 \\
\hline
\end{tabular}




\begin{tabular}{|l|c|c|c|c|}
\hline JOLO & -.02 & -.00 & .08 & .05 \\
\hline Digit Span & $-.31^{*}$ & -.06 & -.17 & -.13 \\
\hline Peg - Dom & $.64^{* *}$ & .14 & .26 & -.19 \\
\hline $\begin{array}{l}\text { Peg - Non } \\
\text { Dom }\end{array}$ & $.38^{*}$ & .12 & .25 & -.13 \\
\hline
\end{tabular}

Notes: Block 1 = Constant + Age; Block 2 = add Age Began; Block 3 = add years in lessons; Block 4 = add current number of hours per week

$* p<0.05, * * p<0.01$

Years in lessons and current number of hours per week playing were both significant predictors of scores on tests of verbal memory, including immediate $(F(1,44)$ $=3.22, p<0.05)$, short delay $(F(1,44)=2.69, p<0.05)$, and long delay free recall $(F(1$, $44)=4.71, p<0.01$ ). For scores on immediate recall, age accounted for $6.0 \%$ of the variance, age began playing accounted for $0.2 \%$, years in lessons accounted for $6.2 \%$, and current hours per week playing accounted for $11.3 \%$ (total $24.3 \%$ of the variance). On the short delay verbal memory task, age accounted for $6.7 \%$, age began playing accounted for $0.2 \%$, years in lessons accounted for $6.8 \%$, and current amount of playing accounted for $7.5 \%$ of the variance in scores (total model accounted for $21.2 \%$ of the variance). Finally, for long delay free recall, age accounted for $17.4 \%$ of the variance, age began accounted for $0.2 \%$, years in lessons accounted for $0.9 \%$, and current amount of playing accounted for $13.5 \%$ of the variance in scores (total model accounted for $32.0 \%$ of the variance). $F$ statistics indicated that there was a significant change between models 3 and $4(p<0.05)$ for immediate memory and between models 3 and 4 for delayed recall $(p<0.01)$. Models for other cognitive test scores were non-significant, including tests of language, executive function, motor function, and visual spatial ability. 


\section{DISCUSSION}

The results of the current study suggest that cognitively normal older adult musicians have higher performance levels within some cognitive domains when compared to non-musicians, even after controlling for education, physical and social activity, and health conditions. The main findings of the study were as follows: 1) musicians outperformed non-musicians on tests of visual spatial ability, naming, and some tests of executive function, and this effect was linear (i.e., high-activity musicians showed the best performance, followed by low-activity and then non-musicians) and 2) within the musician sample, there was a significant relationship between number of years in private lessons and performance on verbal memory tests. Previous literature in this area has failed to account for important confounds such as social activity or overall health, for example. The current study controlled for these variables to test whether group differences were truly reflective of music training and not confounded by variables that have a strong effect on cognitive function in late life. Music training level affected scores on some cognitive tests even when possible confounding variables listed above were controlled. The matching process enabled the current study to demonstrate differences among groups that could not be fully explained through these untapped covariates. Although cross-sectional in design and therefore unable to determine causation, the results suggest that music training may contribute uniquely to differences in cognitive function as individuals age. These results provide more insight into the model initially 
proposed by Richards and Deary (2005; see Figure 1), supporting the idea that music training may provide unique contributions to pre-morbid functioning and $\mathrm{CR}$, which may affect normal age-related cognitive decline (see Figure 2).

\section{Executive Function and Music Training}

Musicians, specifically those with the highest level of training, performed better than non-musician peers on one test of executive function, a test of inhibition and mental control. This effect persisted even after accounting for potential confounding variables including age, education, physical activity, social activity and overall health. During Color-Word Interference Trial 4 (CW4), a version of the Stroop task, the participant must alternate between saying the ink color of the print and reading the color word, which requires a combination of inhibition and processing speed. Differences on tests of executive function were particularly salient when comparing the highest trained musicians with non-musicians, so much so that the standard range of scores for these two groups (i.e., confidence intervals) did not overlap. Consistent with previous research (e.g., Hanna-Pladdy \& MacKay, 2011), there was a linear trend, such that scores of lowactivity musicians (e.g., those with less than 10 years of private lessons) fell in between higher trained musicians and non-musicians; however this middle group was not significantly different from either other group. In regression models, membership in either music group was a significant predictor of scores on the same test of executive function, CW4. Membership in a musician group (high- or low-activity) was the strongest predictor of time on this test, even more so than age, which was highly predictive of most tasks that involved speed. 
CW4 is a test that requires a high degree of mental control under a time constraint. The act of playing a musical instrument also requires a high degree of mental control. The task of alternating between reading and saying the ink color could be compared to sight-reading, which highly trained musicians practice regularly. Sight-reading occurs when a piece of music, unseen before, is placed in front of the musician to play as accurately as possible. The musician must integrate the notation (what note and duration to play that note) as well as dynamic and phrase markings to accurately play this new piece of music. A task like sight-reading requires constant self-monitoring and inhibition. The CW4 task required ongoing self-monitoring and adjustment as well in order to keep moving forward and complete the task. Previous literature has proposed models that liken sight-reading to pattern recognition (Wolf, 1975). Studies have not been published that examine the relationship between sight-reading and executive function.

The results from multiple sets of analysis suggest that musicians may have better executive abilities in some areas and that being a musician predicts test scores in the domain of executive function, particularly within the ability of inhibition. Hanna-Pladdy and MacKay (2011) found that high-activity musicians performed better than nonmusicians on one test of executive function. However, executive function encompasses a broad range of complex, higher order abilities, including inhibition and mental control, set-switching and mental flexibility, and problem solving. The specific type of executive function (as measured by different neuropsychological tests) that distinguished between the musicians and non-musicians across the current and prior studies was inconsistent.

The current study suggested that inhibition was significantly different among groups, an ability that may be related to functioning of the prefrontal cortex (described in 
more detail below). Hanna-Pladdy and MacKay (2011) found that musicians and nonmusicians differed on set-switching and visual tracking (i.e., scores on Trails B), which was inconsistent with the current findings, that showed no differences between groups on Trails B. However, Hanna-Pladdy and MacKay (2011) did not administer multiple tests of executive function, rather only Trails B, which measures set-switching, so they may have been more limited in scope to address possible differences within this domain. Both Trails B and CW4 are timed tests with a high executive demand. Therefore, although the specific tests did not align consistently, these two studies provide evidence that musicians and non-musicians differ in terms of some executive function abilities. If these findings are encompassed under an umbrella within the theory of $\mathrm{CR}$, the results suggest that $\mathrm{CR}$ through intensive music training affects some aspects within the domain of executive function.

The prefrontal cortex (PFC) plays an important role in the domain of executive function and may be more sensitive to aging than other cognitive domains or neuroanatomical areas (Raz \& Rodrigue, 2006). Although there is not a perfect correlation between structure (neuroanatomy) and function (cognition), the relationship remains important to the discussion of the current findings. A review by Aron, Robbins, and Poldrack (2004), discusses how inhibitory responses are shared among subregions of the PFC, including the orbitofrontal cortex (OFC), inferior frontal cortex (IFC), and the dorsolateral prefrontal cortex (DLPFC). Each of the subregions of the PFC are involved in some aspect of inhibition, for example, the OFC is thought to be involved in behavioral inhibition, the right IFC may be involved in cognitive inhibition, and the DLPFC may be involved in memory suppression or inhibition (Aron, et al., 2004). In 
addition, through lesion studies, evidence suggests that the DLPFC in monkeys is related to attention set-shifting, which may map onto inhibition and set-switching in humans, whereas the OFC is responsible for affective-shifting. The review presents support across multiple studies for bilateral activation of the DLPFC in tasks that require inhibition (e.g., Dove, Pollmann, Schubert, Wiggins, \& Cramon, 2000), though not exclusively. Other areas, including the IFC also activate bilaterally during inhibitory tasks. Evidence that the DLPFC interacts with the medial temporal lobe, an area of the brain that is important for encoding memories was also cited in this review. The right IFC and specifically, the pars opercularis (POP) has been found to be involved in executive control, specifically, set-switching and inhibition (Aron et al., 2004). One study also found that the left POP in male musicians had significantly more gray matter volume than the POP in non-musicians (Abdul-Kareem et al., 2011), which could provide some correlational neuroanatomical support for why musicians outperformed nonmusicians on this executive set-switching and inhibitory task.

Other neuroimaging correlates regarding the nature of differences in executive function have been supported more generally in studies with children. For example, bilateral frontal lobe differences in the gray matter in children who are randomly assigned to receive private lessons (Hyde et al., 2009) provide another hypothesis about the cognitive differences in this domain. Although children as an age group are much further removed temporally from the cognitive tests of older adults, some theories of CR would suggest that these changes observed pre-morbidly in the neuroanatomy of children, could present later in life (Stern, 2002). However, causation cannot be determined based on the current study design. It is therefore also a possibility that individuals who inherently 
have better executive function succeed at musical tasks and stay in lessons longer.

Studies that randomly assign children to receive lessons, like the one described above, provide some evidence against this directional hypothesis; however, it is difficult to extend the literature from childhood to late adulthood.

Although the current study found differences among the groups and group membership as a musician predicted performance on the CW4 task of executive function, within the musician group alone there was no relationship between music training variables and tests of executive function. It is possible that not one music training variable is responsible for affecting executive functions, but rather each music training variable provides a small amount of influence on this domain. Therefore, the effect is not observed in bivariate correlations that measure the relationship between scores on one test and one aspect of music training. However, other variables that in previous studies have been highly related to cognitive scores or highly predictive of cognitive scores, specifically age at which a musician began playing, and number of hours a musicians was currently playing (e.g., Hanna-Pladdy \& MacKay, 2011) were unrelated to cognitive functioning in the current sample.

\section{Language and Music Training}

Both subgroups of musicians performed significantly better on a test of confrontation naming (BNT) compared to non-musicians. This finding mirrors that of Hanna-Pladdy and MacKay (2011), who also found that high-activity musicians were significantly better at semantic word retrieval when compared to non-musicians. Membership in either music group was a significant predictor of this same language task 
(BNT), above and beyond other predictor variables, including age, education, physical and social activity, and overall health.

Studies with young and middle aged adults have demonstrated differences between musicians and non-musicians in some language abilities (Brandler \& Rammsayer, 2003; Jakobson et al., 2008). One study proposed a model for the parallel processes of music and language based on distinctive functional neural features (Brown et al., 2006). This study found similar brain activation patterns for reading a sentence and a melody line. Their findings led to a proposed model in which there are multiple levels of connections between music and language, including shared processes for motor and acoustic input (overlapping activation), parallel processes for generating organized sounds (hypothesized lateralization on left for language and on right for music), and distinctive interface areas for each where information is integrated (no overlap on imaging). This theory provides both background and possible mechanism to the current findings that musicians and non-musicians significantly differed on this language task. Although the theory hypothesizes that music and language are somewhat lateralized to separate hemispheres, connectivity between brain regions in musicians may provide some cross-over effects that apply to both their musical and language abilities.

Broca's area and the left inferior frontal gyrus in general (location of Broca's area) have been found to differ between musicians and non-musicians both in children and adults. Bermudez and Zatorre (2005) found that language comprehension areas (e.g., primary auditory cortex) differed in children who were randomly assigned to receive music lessons. Others found that children who were randomly assigned to receive private lessons had better language production than children who did not receive private lessons 
(Gaser \& Schlaug, 2003). As discussed above, there are many parallel processes between language and music, both in terms of functional auditory/motor cortices, as well as more complex syntactic and semantic rules. Examination of specific structures, including subregions of Broca's area, found increased grey matter volume in male musicians in the left pars opercularis (POP) region of Broca's area, but no differences in the left pars triangularis (PTR) or on the right hemisphere of these same areas. Within language processing, the POP (Brodmann's area 44; BA44) is responsible for syntatic processing and phonological working memory, whereas the PTR (BA45) is responsible for semantic processing, rhyming, and lexical decision making (Abdul-Kareem et al., 2011). This provides more evidence that music and language skills are closely tied together. Phonological working memory is the short-term storage of verbal information largely in the left hemisphere (Abdul-Kareem et al., 2011). In the study described above, musicians showed increased volume in the POP, suggesting that either their music training led to an increase in volume, or individuals with better language skills stayed in music lessons longer. This is one potential mechanism that could help explain the magnitude of the differences found between musicians and non-musicians on confrontation naming.

When compared to studies of pathological brain processes, important implications can be extrapolated from the above findings. For example, studies have found that semantic knowledge (measured by the BNT) is one cognitive domain that can show preclinical detection of impairment in individuals who then experience a cognitive decline into AD (see Salmon, 2012). If musicians have significantly better performance on this task of semantic knowledge, they may be protected from the decline seen in this domain in $\mathrm{AD}$. 


\section{Visual Spatial Ability and Music Training}

Musicians' performances were significantly better than non-musicians on multiple tests of visual spatial ability. In addition, membership in the high-activity group for music training, but not low-activity, was a significant predictor of scores on one visual-spatial task (Judgment of Line Orientation; JOLO), but not on the other (Block Design; BD).

There has been little published research comparing musicians and non-musicians on visual spatial functioning in the past few decades. Previous work in the 1980s and 1990s examined differences in visual spatial ability and gender in children. Crosssectional and longitudinal studies (without random assignment) with large sample sizes (120 children) consistently found a difference between children enrolled in music lessons compared to those not enrolled in music lessons (Hassler, 1990), such that children in music lessons showed greater visual spatial ability. In one of the first published studies to measure visual spatial perception and imagery in adults, Brochard, Dufour, and Després (2004), examined processing speed and visual spatial ability. They found that musicians, and particularly those with more expertise, had faster processing times in identifying a visual stimulus (vertical vs. horizontal) compared to non-musicians. Both musicians and non-musicians were better able to visually discriminate horizontal images than vertical images but musicians were faster. A more recent study examining visual attention in musicians, found that musicians were better able to visually attend to information on multiple indices, including reaction time and accuracy (Rodrigues, Loureiro, \& Caramelli, 2013). Furthermore, the musicians' scores were highly correlated with the age at which they began playing. 
Membership in the music training groups predicted performance on one test of visual spatial ability, even after controlling for age, education, social and physical activity and overall health. Just as reading music requires visual spatial ability, training in the ability to read music, or sight-read music may enhance a musician's visual spatial skills that are then generalized to performance on the current test (JOLO). However, in the current study, only one of two visual spatial tasks indicated that music training significantly predicted scores, though scores on these two tests were correlated. Although the tasks both measure visual spatial ability, it is possible that the line orientation task is similar to the kinds of abilities a musician uses when reading music. Learning to read music entails recognizing the distance on the staff of one note to the next, similar to recognizing the distance between two lines that form an angle. This is quite different than processing and replicating a more complex geometric figure.

One mechanism that may help explain the current results is the previous finding that children in music lessons showed increased integration of the visual system with others systems (Hyde et al., 2009). Because musicians may practice integrating visual information with other mental processes while they are reading music, it seems feasible that they are then able to generalize this ability to processing other visual stimuli as well (such as in the line orientation task). However, it is also possible that individuals who have better visual spatial ability excel at specific musical abilities, like sight reading, which is a key competency for a professional musician. Methodological strengths of many studies with children include using longitudinal designs and random assignment and these studies do not find pre-existing differences in those choosing to study music; rather, the experience itself changes the behavior and its corresponding neuroanatomy. 


\section{$\underline{\text { Memory and Music Training }}$}

No differences were observed between musicians and non-musicians on tests of memory (verbal or visual). This is consistent with the study by Hanna-Pladdy \& MacKay (2011), which also failed to find differences in verbal memory between older adult musicians and non-musicians. One possible explanation for the lack of findings across both the current and prior studies is the high sensitivity of verbal memory to the aging process (Salthouse, 2004). Even if musicians show differences in verbal memory compared to non-musicians in adulthood, CR that may have developed across the lifetime does not protect memory in the same way that it protects executive function (theory of neural reserve, Stern, 2002). Another hypothesis for lack of differences in verbal memory between older adult musicians and non-musicians is related to the type of memory measured by neuropsychological tests. For highly trained musicians and nonmusicians alike, music is believed to tap into procedural or implicit memory systems rather than declarative or episodic memory. The common neuropsychological tests used in these studies may not be able to capture implicit memory function in the way that may detect differences, if they exist, between musicians and non-musicians in late life.

The mechanism of neural reserve (Stern, 2002) suggests that executive function may be affected differently by CR than verbal memory and may be related to increased connectivity among brain regions in musicians. Executive function is a complex cognitive domain of higher order abilities that requires the integration and cooperation of many brain regions. Musicians have been shown to have greater density in the corpus callosum, which connects hemispheres, across the lifespan from childhood (Hyde et al., 2009) to middle aged adulthood (Schlaug et al., 1995), as well as differences in white 
matter tracts, including the arcuate fasciculus (AF), which connects temporal and frontal regions (Halwani et a., 2011). The studies of these areas that connect brain regions and are responsible for transmitting information among key structures could suggest that overall, musicians' brains are better connected among brain regions, serving to improve complex, higher order abilities like executive function.

Lack of findings supporting differences between musicians and non-musicians in verbal memory is inconsistent with previous literature from across the lifespan. Studies with children suggest higher verbal abilities and verbal memory (Ho et al., 2003; Moreno et al., 2011) that has translated well to an adult population with multiple studies finding increased verbal memory in adult musicians compared to non-musicians (Brandler \& Rammsayer, 2003; Brown, et al., 2006; Jakobson et al., 2008). Because verbal memory is thought to be more sensitive to aging than other cognitive domains (Salthouse, 2004), it is possible that any differences between the groups that existed in childhood or middle age are no longer significant as the brain aged. In other words, this cognitive ability is more affected by aging and differences did not continue into late life. Differences persisted in other cognitive domains that are less sensitive to the normal aging process (e.g., visual spatial ability).

Within the musician sample, the number of years an individual was in lessons was positively related to verbal memory, including learning, and short and long delayed recall. In other words, as years a musician was enrolled in private lessons increased, verbal memory scores increased as well. The number of years enrolled in lessons and the current number of hours playing an instrument were the best predictors of verbal memory scores, including scores on immediate recall, short and long delay free recall. However, 
the directionality of this finding must also be questioned. For example, it is possible that individuals with higher verbal memory remained in music training longer because of a superior musical ability.

There was also some evidence to suggest that the hours per week a musician played during peak training was related to verbal memory, verbal fluency, and visual spatial ability. Rather than number of hours playing currently, the relationship between scores on these tests and number of hours at peak training approached significance. Because causation cannot be determined from these analyses, the relationship could be explained from either direction. This finding could be interpreted as a long-term effect on cognition, given that peak training for many of these musicians was decades prior to the testing. Perhaps the differences in test scores are picking up on an effect in cognitive function that has persisted across decades. It is also possible that musicians with a better memory recall the number of hours spent playing more accurately or even overestimate the number of hours they played previously in their training. The relationship between verbal and visual spatial abilities and hours of practice at peak training suggests that music training may be related to higher levels of CR. It is possible that there is another variable in the equation functioning as a mediator or moderator on the relationship between prior practice and verbal and visual spatial abilities, but there is to date no literature that could suggest what this variable may be, other than those variables that were controlled for. One possibility is that another variable that was not assessed (e.g., IQ or SES) predicts both cognitive function and music training. 


\section{$\underline{\text { Predictors of Cognition Within Music Trained Elders }}$}

The relationship between hours spent practicing at peak training and cognitive tests also suggests a dose-response effect, in other words, the amount of practicing or playing may be an important factor in determining the effect on cognition. Although no specific cut off (e.g., how many hours of practice per week) can be determined based on the current data, the results suggest that these two variables increase together. Either individuals who with more practice hours have higher scores on tests of verbal memory and visual spatial ability, or individuals who have better memory and visual spatial ability practiced more.

There was an overall lack of support for a relationship between age of acquisition and cognitive scores. Interestingly, the age at which an individual was enrolled in lessons was also not predictive of scores on any neuropsychological tests. The current results suggest that the age at which individuals begins taking lessons (in the current study, age of acquisition was between 2 and 17) is less important than the length of time they are enrolled in lessons. Previous studies support that the number of years an individual is enrolled in lessons greatly affects cognitive functioning (Bailey \& Penhume, 2012; Herdener et al., 2010). Inherently, the number of years an individual is in lessons is related to both the age of acquisition and overall education level. Some studies have found larger effects for individuals who started playing at an earlier age (Bailey \& Penhume, 2012) or are currently playing (Hanna-Pladdy \& MacKay, 2011). The current results may provide some conflicting evidence for a "sensitive" period for learning an instrument. However, the average age of acquisition for high activity musicians was just under 8 years old and for low-musicians this was just over 9 years old, which still fall 
into the sensitive period that has been suggested for learning a musical instrument (Bailey \& Penhume, 2012).

Critical periods and sensitive periods are aspects of experience-expectant development that imply certain experiences are required within a limited time period to maximize their impact [Bruer and Greenough (in Bailey Jr. et al., 2001)]. Critical periods suggest that experiences needed in the development of a system must be obtained by a specific age or the system will not develop correctly. The sensory systems often require experience or exposure during a critical period (Hubel \& Weisel, 1970), but many cognitive abilities or skills, like playing an instrument or learning a second language, are believed to have a sensitive period. A sensitive period suggests that if an experience (e.g., music lessons) is obtained before a particular age, it is easier to develop the skill, but the skill can be developed to a lower level of proficiency after the sensitive period.

Music is a skill that is thought to be developed through a sensitive period. Evidence suggests that children who begin music lessons earlier in life exhibit more drastic functional changes on tasks of visuo-motor and auditory ability than those who begin lessons later in life (Bailey \& Penhune, 2012). The current study did not find consistent evidence to support a sensitive period. The age of acquisition was not related to any test in the battery; rather, years enrolled in lessons was a much more significant variable related to cognitive scores. A sample with a broader range of age of acquisition (e.g., sample including musicians who did not start playing until later in life) may have revealed different results in the current study.

\section{$\underline{\text { Limitations }}$}


Ideally, the sample would have been matched for education, which provides a statistically cleaner approach than to control for this covariate per analysis. Although the sample was large enough to detect some of the larger effect sizes based on sample size estimates, it is possible that some group differences were undetected based on the number of individuals in the sample. Examining confidence intervals and effect size, however, provided further support for the validity of the current results in terms of detecting the extent of differences between the groups.

The sample was quite homogenous in terms of ethnicity and education. The vast majority of the sample was Caucasian and had at least a college degree. There were only two participants who were not white and half of the sample had graduate level training. These factors make the results difficult to generalize. Would older adult musicians with a lower education level still show the same extent of differences on executive function abilities when matched to older adult non-musicians? If the theory of CR is to be supported, an individual with music training should have higher performance than a nonmusician of the same education level on some tests of cognition. It would be interesting to see how a musician with less education performed when compared to a more educated non-musician. It would also be advantageous to examine cognitive functioning between musicians and non-musicians in other racial and ethnic groups like African-Americans who may have higher rates of health problems that can affect cognition (e.g., cardiovascular risk factors). As mentioned previously, it would be interesting to compare older adult musicians who began playing a musical instrument as a child to older adult musicians who began playing in middle age or retirement to see how age of acquisition with this broader range would affect cognitive performance. 
Although social and physical activity level was controlled for and was statistically equivalent across groups, social and physical activity did not strongly predict cognitive scores in any group. There was minimal variability in the levels of physical and social activity as most participants were highly active individuals. Controlling for or at the very least, matching for physical and social activity levels will continue to be important in future research to ensure that effects that are found are not a product of high activity levels and are truly related to music training.

Another limitation was difficulty dividing musician groups. The same arbitrary cutoffs were used as those used by Hanna-Pladdy and MacKay $(2011,2012)$ for consistency; however, defining a "musician" proved ambiguous. Some career musicians (e.g., music educators) were not enrolled in private lessons for more than 10 years, but perhaps were involved in ensembles for decades and only took private lessons at select points during their training. These individuals, although they have a career in music and extensive training, would not pass the cutoff of a "high-activity musician." Similarly, some individuals may have taken private lessons for 15 years but chosen a career in another field and involvement in music activities may be significantly less compared to the previously discussed music educator. It seems likely that people who started taking lessons at an earlier age would have taken lessons for longer, and in turn these individuals would be more likely to have had a career in music and to currently be playing. Gooding and colleagues (2013) addressed the issue of defining a musician by administering a music knowledge test and dividing the group into high-, medium-, and low-knowledge groups based on their test score. A combination of these approaches, that is, asking individuals to report on their music training and testing their music knowledge, may 
prove to be the most beneficial in terms of delineating among musician groups, although it might be most useful to use these factors as continuous variables in regression analyses examining their relationship with cognitive function.

Finally, the study was cross-sectional by design and measured many variables from decades ago based on self-report. There are uncontrolled variables that affect cognition and were not controlled for, including lifestyle factors like history of head injury, diet, alcohol or substance use, or socioeconomic status. These variables could have occurred at any point throughout individuals' lives and could be contributing to differences among groups. In addition, the study relied on the self-report of information from previous decades could be inaccurate (e.g., number of hours spent playing at peak training). The cross-sectional design of the study also raises the possibility of bidirectional explanations. As mentioned previously, it is possible that either musicians performed better within certain cognitive domains as a result of their intensive training or that individuals who are inherently better in certain cognitive domains remain in music longer because of their ability. Longitudinal research with children has provided no support for pre-existing conditions; however, no longitudinal research in adult or older adult populations has been published. Longitudinal research would be able to help provide insight into a causal relationships and directionality of effects as well as correct some of the uncontrolled variables and track the cognition of older adult musicians and non-musicians across years.

\section{Future Research}

Using results from the current study, future research could pursue multiple of paths. It is unclear if differences in cognitive domains outside of executive function and 
memory have been explored because few to no studies have been published that examine other cognitive domains. Either results have failed to reject the null hypothesis, revealing a publication bias, or this research has not been done. The current study provides some early evidence that there are significant differences between musicians and nonmusicians on, for example, visual spatial abilities, one domain that has fewer published studies. Studies need to examine how music training has an effect on cognitive domains like processing speed or attentional capabilities and report not only on group differences, but also on the effect sizes and confidence intervals of these variables. Further research on the mechanisms underlying differences between these groups would lead to a better understanding of the nature of the cognition differences.

The current study should be replicated not only in more heterogeneous populations in terms of ethnicity and education level, but also in terms of level of cognition. Do these results remain consistent in populations of older adults with mild (e.g., mild cognitive impairment) or major neurocognitive disorder (e.g., dementia)? There are many anecdotes of older adult musicians with dementia who are disoriented or cannot recognize their children, yet are still able to play or sing songs from memory. These anecdotes reflect the possible shared or parallel neural pathways for music and language (Brown et al., 2006). Research could examine how this mechanism may be different from other established pathways or from non-musicians.

One factor that would significantly enhance the current study would be to combine neuropsychological test data with neuroimaging data in this population. As noted previously, there is not a direct correlation between neuroanatomy and neuropsychological function, on which the theory of CR depends. It would be 
enlightening to compare neuropsychological test data with imaging data as a part of comparing musicians and non-musicians. Would older musicians and non-musicians be equivalent in terms of neuroimaging findings and still differ between on neuropsychological tests? Alternatively, perhaps musicians show differences in neuroanatomy, as has been found in children and younger adult populations. The extent to which music training affects neuroanatomy in the context of normal age related atrophy is at this point relatively unknown.

The current study also has implications for future interventions research. Age of acquisition was not related or predictive of cognitive scores, but rather the years in lessons. Therefore, would beginning music lessons in mid-life before the onset of cognitive decline (normal or pathological) alter the path or delay this progression? It could be argued that beginning a skill that has established benefits to the cognitive functioning of the brain in later stages of life would provide a boost to skills like executive function and memory. According to Stern (2002), CR is not a static, set level that is achieved at one point in time, but rather is believed to change throughout the lifetime by exposure to activities or environments. Exposure to such an activity as training in a musical instrument may boost an individual's $\mathrm{CR}$ at a time of life that might be critical to cognitive function.

The results also have important implications for music education and public policy. Many schools have undergone budget cuts and begin by cutting funding for the arts programs. The literature from children who are enrolled in music lessons shows significant gains both in terms of cognitive abilities (Hyde et al., 2009; Schlaug, et al., 2005), and perhaps in terms of self-esteem and other social factors (Costa-Giomi, 2004; 
Portowitz, Lichtenstein, Egorova, \& Brand, 2009). It can be stated with some confidence that there is a relationship between music training as a child and cognitive functioning later in life. With a current lack of longitudinal research, the current cross-sectional study is only able to provide some initial evidence that there may be an effect of music lessons on cognitive functioning of the aging brain that perseveres for decades. More research in this area is warranted to determine if there is a causal effect of music lessons on reducing the risk of cognitive decline in late life. Although the current evidence may not be strong enough to support policy recommendation, public policy research examining the benefits of school children enrolled in music lessons compared to those who attend music class through school or who have no more access to music class due to budget cuts could provide additional insight into the music - brain relationship throughout the lifespan.

The current study sheds new light onto the extent of differences between musicians and non-musicians. Although this study does not have the capability to specifically test a CR hypothesis, it is an interesting question to address in the context of highly training musicians. The study is decidedly relevant to a CR hypothesis, however, and has implications for the effect of music training on cognitive reserve whether through a neural reserve or compensatory mechanism. Specifically, the current study provides further support to the unique influence of music training on cognitive differences in late life, consistent with previously proposed models of cognitive aging and decline (Richards \& Deary, 2005, see Figure 1). Although there were limitations to the current study, it provided additional control to confounding variables (e.g., social activity and health factors) that affect cognition and expanded the breadth of neuropsychological domains compared to prior studies. Some results were consistent with Hanna-Pladdy and MacKay 
(2011); some revealed inconsistencies that must be examined further. The results contribute to the existing literature in unique ways and suggest many possible paths for future research endeavors. The current study allows for the recognition of cognitive differences between older adult musicians and non-musicians with significant implications for the role of CR. Future research will bear out whether music training early in life increases objective level of CR or not. 


\section{REFERENCES}

Abbott, R. D. (2004). Walking and Dementia in Physically Capable Elderly Men. JAMA: The Journal of the American Medical Association, 292(12), 1447-1453. doi:10.1001/jama.292.12.1447

Abdul-Kareem, I. A., Stancak, A., Parkes, L. M., \& Sluming, V. (2011). Increased gray matter volume of left pars opercularis in male orchestral musicians correlate positively with years of musical performance. Journal of Magnetic Resonance Imaging, 33(1), 24-32. doi:10.1002/jmri.22391

Albert, M. S., Heller, H. S., \& Milberg, W. (1988). Changes in naming ability with age. Psychology and Aging, 3(2), 173-178. doi:10.1037/0882-7974.3.2.173

Anvari, S. H., Trainor, L. J., Woodside, J., \& Levy, B. A. (2002). Relations among musical skills, phonological processing, and early reading ability in preschool children. Journal of Experimental Child Psychology, 83, 111-130.

Arbuthnott, K., \& Frank, J. (2000). Trail Making Test, Part B as a Measure of Executive Control: Validation Using a Set-Switching Paradigm. Journal of Clinical and Experimental Neuropsychology (Neuropsychology, Development and Cognition: Section A), 22(4), 518-528. doi:10.1076/1380-3395(200008)22:4;1-0;FT518

Aron, A. R., Robbins, T. W., \& Poldrack, R. A. (2004). Inhibition and the right inferior frontal cortex. Trends in cognitive sciences, 8(4), 170-177. 
Ashendorf, L., Jefferson, A. L., Green, R. C., \& Stern, R. A. (2009). Test-retest stability on the WRAT-3 reading subtest in geriatric cognitive evaluations. Journal of Clinical and Experimental Neuropsychology, 31(5), 605-610. doi:10.1080/13803390802375557

Bailey, J., \& Penhune, V. B. (2012). A sensitive period for musical training: contributions of age of onset and cognitive abilities. Annals of the New York Academy of Sciences, 1252(1), 163-170. doi:10.1111/j.1749-6632.2011.06434.x

Bailey Jr., D. B., Bruer, J. T., Symons, F. J., \& Lichtman, J. W. (2001). Critical Thinking About Critical Periods. Baltimore, Maryland: Paul H. Brookes Publishing Co.

Balbag, M. A., Pederson, N. L., \& Gatz, M. (2014). Playing a musical instrument as a protective factor against dementia and cognitive impairment: A population-based twin study. International Journal of Alzheimer's Disease, 2014, DOI: $10.1155 / 2014 / 836748$.

Baltes, P. B., \& Mayer, K. U. (2001). The Berlin aging study: Aging from 70 to 100. Cambridge University Press.

Barnes, L. L., Mendes de Leon, C. F., Wilson, R. S., Bienias, J. L., \& Evans, D. A. (2004). Social resources and cognitive decline in a population of older African Americans and whites. Neurology, 63(12), 2322-2326.

Barulli, D. \& Stern. Y. (2013). Efficiency, capacity, compensation, maintenance, plasticity: Emerging concepts in cognitive reserve. Trends in Cognitive Science, $1235,1-8$. 
Benedict, R., Schretlen, D., Groninger, L., Dobraski, M., \& Shpritz, B. (1996). Revision of the Brief Visuospatial Memory Test: Studies of Normal Performance, Reliability, and Validity. Psychological Assessment, 8(2), 145-153.

Benton, A. L., Varney, N. A., \& Hamsher, K. (1978). Visuospatial Judgment: A Clinical Test. Archives of Neurology, 35(6), 364-367.

Bermudez, P., \& Zatorre, R. J. (2005). Differences in Gray Matter between Musicians and Nonmusicians. Annals of the New York Academy of Sciences, 1060(1), 395399. doi:10.1196/annals. 1360.057

Bialystok, E., \& DePape, A. M. (2009). Musical expertise, bilingualism, and executive functioning. Journal of Experimental Psychology: Human Perception and Performance, 35(2), 565-574. doi:10.1037/a0012735

Bowirrat, A., Friedland, R. P., Farrer, L., Baldwin, C., \& Korczyn, A. (2002). Genetic and environmental risk factors for Alzheimer's disease in Israeli Arabs. Journal of Molecular Neuroscience, 19(1-2), 239-245. doi:10.1007/s12031-002-0040-4

Brandler, S. \& Rammsayer, T. H. (2003). Differences in mental abilities between musicians and non-nusicians. Psychology of Music, 31(2), 123-138. doi: $10.1177 / 0305735603031002290$

Brochard, R., Dufour, A., \& Després, O. (2004). Effect of musical expertise on visuospatial abilities: Evidence from reaction times and mental imagery. Brain and Cognition, 54(2), 103-109. doi:10.1016/S0278-2626(03)00264-1

Brown, S., Martinez, M. J., \& Parsons, L. M. (2006). Music and language side by side in the brain: a PET study of the generation of melodies and sentences. European 
Journal of Neuroscience, 23(10), 2791-2803. doi:10.1111/j.1460-

9568.2006.04785.x

Cavada, C., Company, T., Tejedor, J., Cruz-Rizzolo, R. J., \& Reinoso-Suarez, F. (2000).

The anatomical connections of the macaque monkey orbitofrontal cotex. A review. Cerebral Cortex, 10, 220-242. DOI:10.1093/cercor/10.3.220

Colcombe, S., \& Kramer, A. F. (2003). Fitness effects on the cognitive function of older adults: A meta-analytic study. Psychological Science, 14(2), 125-130.

doi:10.1111/1467-9280.t01-1-01430

Corral, M., Rodriguez, M., Amenedo, E., Sanchez, J. L., \& Diaz, F. (2006). Cognitive reserve, age, and neuropsychological performance in healthy participants. Developmental Neuropsychology, 29(3), 479-491.

Costa-Giomi, E. (2004). Effects of three years of piano instruction on children's academic achievement, school performance and self-esteem. Psychology of Music, 32(2), 139-152. doi:10.117/0305735604041491

D’Ath, P., Katona, P., Mullan, E., Evans, S., \& Katona, C. (1994). Screening, detection and management of depression in elderly primary care attenders. I: The acceptability and performance of the 15 item Geriatric Depression Scale (GDS15) and the development of short versions. Family Practice, 11(3), 260-266. doi:10.1093/fampra/11.3.260

Delis, D. C., Kramer, J. H., Kaplan, E., \& Holdnack, J. (2004). Reliability and validity of the Delis-Kaplan Executive Function System: An update. Journal of the International Neuropsychological Society, 10(02).

doi:10.1017/S1355617704102191 
Delis, D. C., Kramer, J. H., Kaplan, E., \& Ober, B. A. (1987). California Verbal Learning Test. San Antonio, Tex.: The Psychological Corporation.

Di Carlo, A., Baldereschi, M., Amaducci, L., Lepore, V., Bracco, L., Maggi, S., ... Inzitari, D. (2002). Incidence of dementia, Alzheimer's disease, and dascular dementia in Italy: The ILSA study. Journal of the American Geriatrics Society, 50, $41-48$.

Dove, A., Pollmann, S., Schubert, T., Wiggins, C. J., \& von Cramon, D. Y. (2000). Prefrontal cortex activation in task switching: an event-related fMRI study. Cognitive brain research, 9(1), 103-109.

Elwood, R. W. (1995). The California Verbal Learning Test: Psychometric characteristics and clinical application. Neuropsychology Review, 5(3), 173-201. doi:10.1007/BF02214761

Ewer, M., Walsh, C., Trojanowski, J. Q., Shaw, L. M., Petersen, R. C., Jack Jr., C. R., Feldman, H. H., et al. (2012). Prediction of conversion from mild cognitive impairment to Alzheimer's dementia based on upon biomarkers and neuropsychological test performance. Neurobiology of aging, 33, 1203-1214. doi: 10.1016/j.neurobiolaging.2010.10.019

Ferraro, F. R., \& Lowell, K. (2010). Boston Naming Test. In I. B. Weiner \& W. E. Craighead (Eds.), The Corsini Encyclopedia of Psychology. Hoboken, NJ, USA: John Wiley \& Sons, Inc. Retrieved from http://doi.wiley.com/10.1002/9780470479216.corpsy0139 
Fratiglioni, L., Wang, H.-X., Ericsson, K., Maytan, M., \& Winblad, B. (2000). Influence of social network on occurrence of dementia: A community-based longitudinal study. The Lancet, 355, 1315-1319.

Fujioka, T. (2006). One year of musical training affects development of auditory corticalevoked fields in young children. Brain, 129(10), 2593-2608.

doi:10.1093/brain/awl247

Gaser, C., \& Schlaug, G. (2003). Gray matter differences between musicians and nonmusicians. Annals of the New York Academy of Sciences, 999(1), 514-517. doi:10.1196/annals. 1284.062

Ghisletta, P., McArdle, J. J., \& Lindenberger, U. (2006). Longitudinal cognition-survival relations in old and very old age: 13-year data from the Berlin Aging Study. European Psychologist, 11(3), 204-223. doi:10.1027/1016-9040.11.3.204

Goldstein, F. C., Ashley, A. V., Endeshaw, Y., Hanfelt, J., Lah, J. J., \& Levey, A. I. (2008). Effects of hypertension and hypercholesterolemia on cognitive functioning in patients with Alzheimer's disease. Alzheimer Disease \& Associated Disorders, 22. 336-342.

Gooding, L. F., Abner, E. L., Jicha, G. A., Kryscio, R. J., \& Schmitt, F. A. (2013). Musical training and late life cognition. American Journal of Alzheimer's Disease \& Other Dementia, 29, 333-343. DOI: 10.1177/1533317513517048

Halwani, G. F., Loui, P., Rüber, T., \& Schlaug, G. (2011). Effects of practice and experience on the Arcuate Fasciculus: Comparing singers, instrumentalists, and non-musicians. Frontiers in Psychology, 2. doi:10.3389/fpsyg.2011.00156 
Hanna-Pladdy, B., \& Gajewski, B. (2012). Recent and past musical activity predicts cognitive aging variability: Direct comparison with general lifestyle activities. Frontiers in Human Neuroscience, 6. doi:10.3389/fnhum.2012.00198

Hanna-Pladdy, B., \& MacKay, A. (2011). The relation between instrumental musical activity and cognitive aging. Neuropsychology, 25(3), 378-386. doi:10.1037/a0021895

Hassler, M. (1990). Functional cerebral asymmetries and cognitive abilities in musicians, painters, and controls. Brain and Cognition, 13, 1-17.

Herdener, M., Esposito, F., di Salle, F., Boller, C., Hilti, C. C., Habermeyer, B., ... Cattapan-Ludewig, K. (2010). Musical training induces functional plasticity in human hippocampus. Journal of Neuroscience, 30(4), 1377-1384. doi:10.1523/JNEUROSCI.4513-09.2010

Ho, Y.-C., Cheung, M.-C., \& Chan, A. S. (2003). Music training improves verbal but not visual memory: Cross-sectional and longitudinal explorations in children. Neuropsychology, 17(3), 439-450. doi:10.1037/0894-4105.17.3.439

Hubel, D. H. \& Wiesel, T. N. (1970). The period of susceptibility to the physiological effects of unilateral eye closure in kittens. Journal of Physiology, 206, 419-436.

Hyde, K. L., Lerch, J., Norton, A., Forgeard, M., Winner, E., Evans, A. C., \& Schlaug, G. (2009). Musical training shapes structural brain development. Journal of Neuroscience, 29(10), 3019-3025. doi:10.1523/JNEUROSCI.5118-08.2009 Jakobson, L. S., Lewycky, S. T., Kilgour, A. R., \& Stoesz, B. M. (2008). Memory for verbal and visual material in highly trained musicians. Music Perception, 26(1), 41-55. doi:10.1525/mp.2008.26.1.41 
Jones, R. N., Manly, J., Glymour, M. M., Rentz, D. M., Jefferson, A. L., \& Stern, J. (2011). Conceptual and measurement challenges in research on cognitive reserve. Journal of the International Neuropsychological Society, 17, 593-601. DOI: $10.1017 / \mathrm{S} 1355617710001748$.

Kaplan, E. F., Goodglass, H., \& Weintraub, S. (2978, 1983). The Boston Naming Test: Experimental edition (1978). Boston: Kaplan \& Goodglass. ( $2^{\text {nd }}$ ed., Philadelphia: Lea \& Febiger.

Karp, A. (2004). Relation of education and occupation-based socioeconomic status to incident Alzheimer's disease. American Journal of Epidemiology, 159(2), 175183. doi:10.1093/aje/kwh018

Katz, S. (1983). Assessing self-maintenance: Activities of daily living, mobility, and instrumental activities of daily living. Journal of the American Geriatrics Society, 31(12), 721-727.

Lawton, M. P., \& Brody, E. M. (1969). Assessment of older people: Self-maintaining and instrumental activities of daily living. Gerontologist, 9, 179-186.

Lindenberger, U., \& Baltes, P. (1997). Intellectual functioning in old and very old age: Cross-sectional results from the Berlin Aging Study. Psychology and Aging, 12(3), $410-432$.

Logsdon, R., Gibbons, L. E., McCurry, S. M., \& Teri, L. (1999). Quality of life in Alzheimer's disease: Patient and caregiver reports. Journal of Mental Health \& Aging, 5(1), 21-32. 
Marra, C., Silveri, M. C., \& Gainotti, G. (2000). Predictors of cognitive decline in the early stage of probable Alzheimer's disease. Dementia and Geriatric Cognitive Disorders, 11(4), 212-218. doi:10.1159/000017239

Moreno, S., Bialystok, E., Barac, R., Schellenberg, E. G., Cepeda, N. J., \& Chau, T. (2011). Short-term music training enhances verbal intelligence and executive function. Psychological Science, 22(11), 1425-1433. doi:10.1177/0956797611416999

Matthews, C. G., \& Klove, K. (1964). Instruction manual for the Adult Neuropsychology Test Battery. Madison, Wisc.: University of Wisconsin Medical School.

Nevriana, A., Riono, P., Rahardjo, T. B. W., \& Kusumadjati, A. (2013). Lifetime musical activities and cognitive function of the elderly. Kesmas, 7, 517-.

Partington, J. E., \& Leiter, R. G. (1949). Partington's Pathway Test. The Psychological Service Center Bulletin, 1, 9-20.

Portowitz, A., Lichtenstein, O., Egorova, L., \& Brand, E. (2009). Underlying mechanisms linking music education and cognitive modifiability. Research Studies in Music Education, 31(2), 107-128. doi:10.1177/1321103X09344378

Raz, N., \& Rodrigue, K. M. (2006). Differential aging of the brain: Patterns, cognitive correlates and modifiers. Neuroscience \& Biobehavioral Reviews, 30(6), 730-748. doi:10.1016/j.neubiorev.2006.07.001

Revell, A. J., Caskie, G. I. L., Willis, S. L., \& Schaie, K. W. (2009). Factor structure and invariance of the Quality of Life in Alzheimer's disease (QoL-AD) Scale. Experimental Aging Research, 35(2), 250-267. doi:10.1080/03610730902720521 
Richards, M., \& Deary, I. J. (2005). A life course approach to cognitive reserve: A model for cognitive aging and development? Annals of Neurology, 58(4), 617-622. doi:10.1002/ana.20637

Richards, M., Hardy, R., \& Wadsworth, M. (2003). Does active leisure protect cognition? Evidence from a national birth cohort. Social Science \& Medicine, 56, 785-792.

Ridder, K. L., Gallagher-Thompson, D., \& Thompson, L. W. (2004). California older person's pleasant events schedule: Manual.

Rodrigues, A. C., Loureiro, M. A., \& Caramelli, P. (2013). Long-term musical training may improve different forms of visual attention ability. Brain and Cognition, 82(3), 229-235. doi:10.1016/j.bandc.2013.04.009

Ross, T. P., Foard, L. E., Hiott, F. B., \& Vincent, A. (2003). The reliability of production strategy scores for the Ruff Figural Fluency Test. Archives of Clinical Neuropsychology, 18, 879-891.

Ruff, R. (1996). Ruff Figural Fluency Test. Odessa, FL: PAR.

Ruff, R. M., Light, R. H., Parker, S. B., \& Levin, H. S. (1996). Benton Controlled Oral Word Association Test: Reliability and updated norms. Archives of Clinical Neuropsychology, 11(4), 329-338.

Ruff, R. M., \& Parker, S. B. (1993). Gender- and age- specific changes in motor speed and eye-hand coordination in adults: Normative values for the Finger Tapping and Grooved Pegboard Tests. Perceptual and Motor Skills, 76(3c), 1219-1230. doi:10.2466/pms.1993.76.3c.1219 
Salmon, D. (2012). Neuropsychological features of mild cognitive impairment and preclinical Alzheimer's disease. Pardon, M-C. \& Bondi, M. W. (eds). Behavioral Neurobiology of Aging, 187-212.

Salthouse, T. A. (2004). What and when of cognitive aging. Current Directions in Psychological Science, 13(4), 140-144.

Sánchez-Cubillo, I., Periáñez, J. A., Adrover-Roig, D., Rodríguez-Sánchez, J. M., RíosLago, M., Tirapu, J., \& Barceló, F. (2009). Construct validity of the Trail Making Test: Role of task-switching, working memory, inhibition/interference control, and visuomotor abilities. Journal of the International Neuropsychological Society, 15(03), 438. doi:10.1017/S1355617709090626

Schaie, K. W. (1993). The Seattle Longitudinal Study: A thirty-five year inquiry of adult intellectual development. Zeitschrift für Gerontologie, 26, 509-518.

Schlaug, G., Norton, A., Overy, K., \& Winner, E. (2005). Effects of music training on the child's brain and cognitive development. Annals of the New York Academy of Sciences, 1060(1), 219-230. doi:10.1196/annals.1360.015

Schlaug, G., Jäncke, L., Huang, Y., Staiger, J. F., \& Steinmetz, H. (1995). Increased corpus callosum size in musicians. Neuropsychologia, 33(8), 1047-1055.

Shahin, A., Roberts, L. E., \& Trainor, L. J. (2004). Enhancement of auditory cortical development by musical experience in children. NeuroReport, 15(12), 1917-1921.

Spreen, O. \& Strauss, E. A Compendium of Neuropsychological Tests: Administration, Norms, and Commentary. Oxford University Press, New York, 1998. 
Stern, Y. (2002). What is cognitive reserve? Theory and research application of the reserve concept. Journal of the International Neuropsychological Society, 8, 448460.

Stern, Y. (2003). The concept of cognitive reserve: A catalyst for research. The Journal of Clinical and Experimental Neuropsychology, 25, 589-593.

Stern, Y. (2009). Cognitive reserve. Neuropsychologia, 47(10), 2015-2028. doi:10.1016/j.neuropsychologia.2009.03.004

Stewart, A. L., Mills, K. M., King, A. C., Haskell, W., Gillis, D., \& Ritter, P. L. (2001). CHAMPS physical activity questionnaire for older adults: Outcomes for interventions. Medicine \& Science in Sports \& Exercise, 33, 1126-1141. doi: 10.1097/00005768-200107000-00010.

Stewart, L., Walsh, V., \& Frith, U. (2004). Reading music modifies spatial mapping in pianists. Perception \& Psychophysics, 66(2), 183-195.

Van Gelder, B. M., Tijhuis, M. A. R., Kalmijn, S., Giampaoli, S., Nissinen, A., \& Kromhout, D. (2004). Physical activity in relation to cognitive decline in elderly men: The FINE Study. Neurology, 63(12), 2316-2321. doi:10.1212/01.WNL.0000147474.29994.35

Verhaeghen, P., \& Salthouse, T. A. (1997). Meta-analyses of age-cognition relations in adulthood: Estimates of linear and nonlinear age effects and structural models. Psychological Bulletin, 122(3), 231-249.

Wang, H. X. (2002). Late-life engagement in social and leisure activities is associated with a decreased risk of dementia: A longitudinal study from the Kungsholmen 
Project. American Journal of Epidemiology, 155(12), 1081-1087. doi:10.1093/aje/155.12.1081

Wechsler, D., Coalson, D. L., \& Raiford, S. (2008). WAIS-IV Technical and Interpretive Manual. In Wechsler Adult Intelligence Scale-Fourth Edition.

Weuve, J., Kang, J. H., Manson, J. E., Breteler, M., Ware, J. H., \& Grodstein, F. (2004). Physical activity, including walking, and cognitive function in older women. Journal of American Medical Association, 292, 1454-1461.

Wilkinson, G. S. (1993). Wide Range Achievement Test 3. Wilmington, DE: Wide Range, Inc.

Wolf, T. (1975). A cognitive model of musical sight-reading. Journal of Psycholinguistic Research, 5, 143-171.

Woods, S. P., Delis, D. C., Scott, J. C., Kramer, J. H., \& Holdnack, J. A. (2006). The California Verbal Learning Test - second edition: Test-retest reliability, practice effects, and reliable change indices for the standard and alternate forms. Archives of Clinical Neuropsychology, 21, 413-420. doi: 10.1016/j.acn.2006.06.002 


\section{CURRICULUM VITA}

NAME: Jessica Vemich Strong

ADDRESS: Psychology Service

Boston VA Healthcare System

$150 \mathrm{~S}$. Huntington Ave.

Boston, MA 02130-4820

DOB: $\quad$ Kalamazoo, Michigan - June 4, 1986

EDUCATION

\& TRAINING: $\quad$ B.M., Piano Performance

DePauw University

2004-2009

B.A., Psychology \& German

DePauw University

2004-2009

M.A., Clinical Psychology

University of Louisville

2010-2012

Ph.D., Clinical Psychology

University of Louisville

2010-2015

AWARDS: $\quad$ Clinical Fellow in Psychiatry, Harvard Medical School 2014-2015

Teaching Fellow, Dept of Psychiatry Boston University School of Medicine

2014-2015

Fulbright Award

2009-2010

DePauw University Senior Thesis Seminar Award 2008 
PUBLICATIONS: $\quad$ Strong, J. V. \& Mast, B. T. (2013). The impact of depression on the expression of caregiver burden and grief. The Clinical Gerontologist, 36, 440-450. doi: 10.1080/07317115.2013.816816

Ross, S. R., Keiser, H. N., Strong, J. V., \& Webb, C. M. (2013) Reinforcement Sensitivity Theory and Symptoms of Personality Disorder: Specificity of the BIS in Cluster C and BAS in Cluster B. Personality and Individual Differences, 54, 289-293. doi: 10.1016/j.paid.2012.09.020

Stricker, N. H., Weissberger, G., Strong, J., Smith, G. E. \& Bondi, M. W. (in preparation) Keeping neuropsychology relevant for the detection of Alzheimer's disease in the biomarker era: A review of diagnostic accuracy studies and future directions.

\section{NATIONAL MEETING}

PRESENATIONS:

Strong, J. V. \& Mast, B. T. (2014, November). Musical Training, Hypertension, and Neuropsychological Functioning in Older Adult Musicians. Presented the $67^{\text {th }}$ annual meeting of the Gerontological Society of America, Washington D.C.

Strong, J. V. \& Mast, B. T. (2012, November). The Marwit Meuser Mini Caregiver Grief Inventory. Presented at the $65^{\text {th }}$ annual meeting of the Gerontological Society of America, San Diego, CA.

Strong, J. V., Holley, C. K., \& Mast, B. T. (2011, November) The Grief Profile for Caregivers of Persons with Dementia. Presented at $64^{\text {th }}$ annual meeting of the Gerontological Society of America. Boston, MA.

Strong, J. V., Ross, S. R., \& Webb, C. M. (2010, July) Gray's BAS in cluster B and BIS in cluster C: Further evidence using the Schedule for Nonadaptive and Adaptive Personality. Presented at the $15^{\text {th }}$ annual meeting of the European Conference on Personality. Brno, Czech Republic.

Strong, J. V., Somerville, E., \& Stark, S. (2008, July) Adherence rates of home modifications for older adults. Presented at Washington University, St. Louis, MO.

Webb, C. M., Strong, J. V., \& Ross, S. R. (2008, May) The relationship between executive functioning and symptoms of personality disorder. Presented at the $20^{\text {th }}$ annual meeting of the Association for Psychological Science, Chicago, IL

INVITED

PRESENTATIONS: 
Strong, J. (2014, October). One DePauw Alumni's path to a dissertation on Neuropsychological Differences between Older Adult Musicians and NonMusicians. Presented as part of Psychology Speaker Series, DePauw University, Greencastle, IN. 